\title{
Efficacy of anti-TNF-alpha monoclonal antibodies in inflammatory bowel disease treatment
}

This article was published in the following Dove Press journal:

International Journal of Interferon, Cytokine and Mediator Research

23 October 2013

Number of times this article has been viewed

\section{Amélie Deleporte' \\ Stéphanie Viennot ${ }^{2}$ \\ Benoît Dupont ${ }^{2}$ \\ Cyrielle Gilletta ${ }^{2}$ \\ Manon Allaire ${ }^{2}$ \\ Frédérique Prévost ${ }^{1}$ \\ Jean-Marie Reimund ${ }^{2,3}$}

'Department of Internal Medicine, Digestive Medical Oncology, Institut Jules Bordet, Brussels, Belgium; ${ }^{2} \mathrm{CHU}$ de Caen, Service d'Hépato-

Gastro-Entérologie et Nutrition, Pôle Cancérologie et Médecine d'Organes, Caen, France; ${ }^{3}$ Université de Caen Basse-Normandie, UFR de Médecine, Laboratoire Microenvironnement Cellulaire et Pathologies, Caen, France

Correspondence: Jean-Marie Reimund Service d'Hépato-Gastro-Entérologie et Nutrition, Pôle Cancérologie et Médecine d'Organes, CHU de Caen,

Avenue de la Côte de Nacre,

CS 3000I, I4033 Caen Cedex 9, France

Tel +33231064540

Fax +33231064545

Email jm.reimund.gcb@gmail.com
Abstract: Pathogenesis of inflammatory bowel disease (IBD), including Crohn's disease (CD) and ulcerative colitis (UC), continues to drive basic research to better decrypt their causal factor(s). Several key mediators involved in IBD pathogenesis have been identified and are considered as potential therapeutic targets. The best example of translational research (from bench to bedside) success is the demonstration that tumor necrosis factor (TNF)-alpha plays a critical role in IBD pathophysiology and that several monoclonal antibodies directed against TNF-alpha are effective tools in IBD treatment. Numerous high quality clinical trials have proven that monoclonal anti-TNF-alpha antibodies (infliximab, adalimumab, and certolizumab pegol) are of great therapeutic value in luminal and/or fistulizing CD or UC, both as induction and as maintenance treatment (health authority approval is dependent on the country and on the antibody being used). Therefore, it is not excessive to state that they have become the mainstay in IBD therapy in 2013. Nevertheless, some important questions related to their use (in particular their long-term use) should be answered in the coming years. This paper reviews the most important data on efficacy and tolerance, and also aims to highlight several future goals for IBD treatment with anti-TNF-alpha monoclonal antibodies.

Keywords: anti-TNF-alpha monoclonal antibodies, inflammatory bowel disease, Crohn's disease, ulcerative colitis, therapeutic efficacy

\section{Introduction}

The worldwide and continuous increase in the incidence of inflammatory bowel disease (IBD), which includes Crohn's disease (CD) and ulcerative colitis (UC), represents a real therapeutic challenge in Western countries, but also, increasingly, in geographical areas usually considered less concerned with IBD. In addition, IBD mostly affects young adults, exposing them to relapsing digestive and non-digestive clinical symptoms, as well as to a significant decrease in quality of life and/or to disabling complications. Therefore, it is crucial to further improve our knowledge of IBD pathogenesis and develop new effective and less harmful treatments.

Before examining in detail how tumor necrosis factor (TNF)-alpha antibodies have changed the treatment of IBD, this introduction aims to give a summarized overview of the current pathophysiological hypotheses - as these hypotheses have been the basis of anti-TNF-alpha antibody development - before proceeding to the identification of potential targets for future therapeutics. 
TNF-alpha and IBD pathogenesis: the first steps of a rational decryption of immune and inflammatory responses leading

\section{to a crucial change in treatment possibilities and strategies}

Following the first reports of the discovery of cytokines and the suggestion of their key role in immune and inflammatory responses - in particular TNF-alpha, previously termed cachectin $^{1}$ - research in both basic and clinical areas began in the mid-1980s. Before consideration of TNF-alpha as an important cytokine mediating IBD-inappropriate immune responses leading to intestinal lesions and, as a result, IBD clinical symptoms, the role of other cytokines, eg, interleukin (IL)-2, was suspected but was not conclusive. ${ }^{2-7}$ However, these data reinforced the hypothesis that monocytes, macrophages, and/or T-lymphocytes participated in IBD pathogenesis - at least as a "bypass" between the causal event(s) (still not clearly identified) - and the observed intestinal damage and their related clinical symptoms and complications. Therefore, considering TNF-alpha's physiological and pathogenic properties, and after Murch et al reported increased TNF-alpha serum concentrations in childhood IBD, ${ }^{8}$ we and others reported a relationship between TNF-alpha and IBD by examining TNF-alpha serum, stool, and/or intestinal mucosal concentrations. ${ }^{9-13}$ In addition, we reported that the level of TNF-alpha was not only increased in inflamed CD or UC mucosa, but was also increased in normal appearing mucosa, at least in $\mathrm{CD} .{ }^{14}$ This observation, as well as data from Schreiber et al that showed that high production of TNF-alpha and IL-1 beta in short-term culture of human lamina propria mononuclear cells predicted risk of relapse within 12 months, ${ }^{15}$ probably explained, at least in part, why postoperative recurrence is frequent in $\mathrm{CD} .{ }^{16}$ Taken together, TNF-alpha appeared to be a logical target for IBD treatment. During this period, anti-TNF-alpha antibodies were developed, firstly chimeric antibodies (ie, infliximab), followed by humanized and human anti-TNF-alpha antibodies (adalimumab and certolizumab pegol, respectively). As a result, the first report of efficacy of anti-TNF-alpha antibodies in CD was published in 1995 by van Dullemen et al who used the monoclonal antibody cA2 (infliximab). ${ }^{17}$ In parallel, anti-TNF-alpha receptor (anti-TNFR) antibodies were developed in inflammatory rheumatologic diseases. Unfortunately these antibodies were found to be ineffective in IBD, in particular in CD as they have not been tested in UC. ${ }^{18-20}$ A number of key therapeutic trials demonstrated that anti-TNF-alpha antibodies strongly improved IBD outcome, ${ }^{21-25}$ and therefore should be considered as an outstanding and revolutionary progress for treatment of IBD patients, either in $\mathrm{CD}$ or in UC.

\section{The rapidly growing identification of new important pathogenetic factors: a theoretical opportunity to increase our therapeutic armamentarium for treating IBD patients}

Despite the considerable therapeutic impact of anti-TNFalpha antibody treatment in IBD, scientists and clinicians should continue to identify new therapeutic tools that are possibly more effective and/or safer than anti-TNF-alpha antibodies, and also identify molecules that provide relevant alternatives to anti-TNF-alpha antibody treatments, in particular for nonresponders, for patients who experienced loss of response, and for patients who need to stop anti-TNF-alpha antibody therapy because of unacceptable side effects. To achieve these objectives, the most important and difficult challenge to overcome is to find new relevant therapeutic targets, and as a consequence, to have a better and integrated understanding of $\mathrm{CD}$ and $\mathrm{UC}$ pathophysiology despite the more complex landscape provided by advances in genetics, knowledge of microbiota function in IBD, and the continuous unraveling of knowledge of intestinal innate and adaptative inflammatory and immune responses.

It is now commonly accepted that IBD develops in genetically susceptible individuals. Nevertheless, as IBDs are considered as polygenetic diseases, "gene therapy" seems outside the scope of future therapeutic developments. However, identification of genetic defects has increased our understanding of IBD pathogenesis. First, several defects clearly indicate that the intestinal microbiota probably plays an essential role in IBD onset. These results, in particular from data suggesting a link between defects in genes encoding factors involved in the inflammatory and immune responses to intestinal bacteria, including pattern recognition receptors from the nucleotide-binding leucine-rich repeats receptor family (the first that was associated with CD being the NOD2/CARD15 gene) $)^{26,27}$ and the toll-like receptor (TLR) family (eg, TLR4), ${ }^{28}$ genes encoding proteins involved in the autophagic process (eg, autophagy-related 16-like 1 protein gene ATG16L1 and immunity-related GTPase family, M protein gene $I R G M)$, or genes important for the unfolded protein response,,$^{29,30}$ greatly improve our understanding of the key pathways contributing to IBD. However, despite increasing amounts 
of data to indicate an imbalance in IBD patients' microbiota, it is not known if this dysbiosis is a primary factor (eg, resulting from early abnormalities occurring during tolerance acquisition), a secondary factor due to an inappropriate inflammatory/immune response to an initially normal intestinal flora, or if it is a consequence of the presence of harmful pathogen(s) usually not found in, or repressed by, the intestinal microbiota. ${ }^{31-33}$ Secondly, other genetic defects clearly affect the ability of the intestinal inflammatory/immune system - either innate or adaptative - to respond adequately to luminal factors physiologically cleared by intestinal transit, which are able to cross the epithelial barrier - demonstrated to be defective in IBD. ${ }^{34}$ This complex interplay allowed identification of several potentially new therapeutic targets, in particular molecules involved in the intestinal inflammatory/immune network such as cytokines (eg, IL-12, IL-23, IL-13, etc) and integrins (eg, $\alpha 4 \beta 7$ integrins). ${ }^{35,36}$ Nevertheless, the tools triggering these targets (some of which have failed to demonstrate clinical relevance, and others that are currently being tested in clinical trials or are at a preclinical stage) relate to late disease stages following disease onset. New avenues are open to potentially increase our therapeutic armamentarium in IBD over the coming years.

\section{Therapeutic tools in IBD}

The main objectives of IBD treatment are to induce clinical remission and to maintain it for as long as possible, to decrease the need for steroids (due to the side effects when used often or for long periods of time), to decrease the rate of uncontrolled disease complications, and to limit patients' need for surgical treatment and their potential long-term consequences, thereby improving the patient's quality of life. Until recently, treatment decisions were principally based on clinical response or remission. During the last few years, this clinical objective has been criticized as data suggest that on a long-term basis, mucosal healing as the main therapeutic objective should be considered more accurate and rational than clinical remission only. ${ }^{37}$

\section{From 5-aminosalicylates to steroids to immunosuppressants (purines and methotrexate)}

This topic has been reviewed by Pithadia and Jain. ${ }^{38}$ Aminosalicylates have represented the first line therapy in IBD. Nowadays, their use is restricted to treatment of mild to moderate UC, and as a chemopreventive therapy against dysplasia and colorectal cancer in extensive and chronic colonic IBD. Historically, sulfasalazine - a combination of 5-aminosalicylic acid (5-ASA) and sulfapyridine linked by an azo bond - was the first aminosalicylate used in IBD. However, because it was demonstrated that sulfapyridine did not significantly contribute to sulfasazine's therapeutic properties but instead was responsible for most of its side effects, pure 5-ASA derivatives have been developed. As it is beyond the scope of this review, we will not discuss in detail their therapeutic use in IBD. To summarize: (i) 5-ASA can be administered orally and/or locally (enemas or suppositories); (ii) 5-ASA suppositories are principally active in mild to moderate proctitis, or - in combination with oral 5-ASA - in mild or moderate extended UC in patients presenting clear symptoms of rectal syndrome; (iii) 5-ASA enemas are used in left-sided mild or moderate UC, alone or - if they are not effective - in combination with local steroids or oral 5-ASA as a second line treatment; (iv) oral 5-ASA represents the first line treatment for mild to moderate extensive (ie, extended over the left colonic flexure) UC; (v) oral 5-ASA has been demonstrated to prevent colonic IBD-associated dysplasia, in particular UC-associated dysplasia (at a dose half of that used for treating UC with mild to moderate flare-ups); (vi) 5-ASA either locally or orally administered probably does not contribute to maintenance of medically-induced remission in IBD; (vii) 5-ASA is currently not considered as an effective option in CD treatment strategy, and finally (viii) the role of 5-ASA to prevent postoperative recurrence in CD patients with ileocolonic resection, although debated, is supported by several authors, but only in patients having the lowest risk of recurrence. ${ }^{39,40}$

In $\mathrm{CD}$, in mild to moderate $\mathrm{UC}$ failing 5-ASA treatment, and in patients with severe UC attacks, corticosteroids are considered as the reference treatment. In uncomplicated CD, oral corticosteroids, such as prednisone (or prednisolone), are the first treatment prescribed to patients at a dose of $1 \mathrm{mg} / \mathrm{kg}$ of body weight/day. In cases of nonresponse, intravenous (IV) corticosteroids can be tried for 5 to 7 days. Oral prednisone (or prednisolone) at a daily dose of $40 \mathrm{mg}$ also represents the standard treatment for severe UC or for cases of 5-ASA failure in moderate UC. Finally, IV corticosteroids are also considered as the initial treatment for fulminant colitis. For this particular clinical presentation, their use should follow a strict therapeutic scheme adapted from the initial protocol established by Truelove and Witts. ${ }^{41}$ Notably, corticosteroids have never been proven as a good tool to obtain mucosal healing. ${ }^{42}$ In addition, considering their short- and long-term side effects, corticosteroids are never used as a maintenance treatment. 
Immunosuppressants - we focus here on purine analogs and methotrexate - have been increasingly used during the last decade specifically for maintenance treatment (purine analogs) and for induction and maintenance treatment (methotrexate). Azathioprine (AZA) and 6-mercaptopurine (6-MP) cannot be used for induction therapy as their efficacy is reached only after 3 months in most of patients. They are principally used in corticosteroid-dependent patients to achieve steroid-free remission and remission maintenance. Until now they have also been considered as the first line treatment to prevent early postoperative recurrence in CD patients who require ileocecal or ileocolonic resection and who have medium or high risk of early relapse. The duration of maintenance treatment with purine analogs has not been definitively established but several studies indicate that they should be taken for at least 5 years after initiation. ${ }^{43}$ To improve their efficacy/tolerance balance, their increasing use during the last two decades has prompted several strategies to optimize their use. ${ }^{44}$ Methotrexate, administered subcutaneously once-weekly initially at a dose of $25 \mathrm{mg} /$ week and progressively decreasing to a dose of $15 \mathrm{mg} /$ week if active, is often more rapidly active than purine analogs (after a 2 month delay). Therefore, methotrexate is sometimes used as an induction treatment in mild to moderate corticosteroid refractory IBD. Nevertheless, like 6-MP and AZA, methotrexate is more frequently used as a maintenance treatment in corticosteroid-dependent patients who have failed, or who present with serious adverse events, to purine analogs. Its teratogenicity is the major restriction for its use in young patients who potentially wish to have children.

\section{Mechanism of action, efficacy, safety, and tolerance of anti-TNF-alpha treatments}

As stated earlier, the availability of anti-TNF-alpha antibody therapy for IBD represents an outstanding progress in patient management.

\section{Mechanisms of therapeutic action of anti-TNF-alpha antibodies in IBD}

The initial hypotheses leading to the development of antiTNF-alpha antibodies as an IBD therapeutic tool resulted in the generation of data indicating that TNF-alpha represents a key cytokine involved in CD and UC. ${ }^{8-15}$ TNF-alpha is a transmembrane homotrimeric protein that is mainly expressed on, and secreted by, activated macrophages and T-lymphocytes. After proteolytic cleavage of the extracellular domain of the membrane-bound TNF-alpha, these cells release soluble TNF-alpha. Both forms of TNF-alpha are able to bind to TNF-alpha receptor (TNFR)-1 or -2. After binding to TNFR-1 or -2, TNF-alpha activates several intracellular transduction pathways that lead to its physiological and pathological effects. TNF-alpha has been demonstrated to be an essential mediator in numerous immunological responses that include the downstream induction of ILs (eg, IL-1, IL-6, interferon- $\gamma$ ), adhesion molecules (eg, intracellular adhesion molecule-1), production of other inflammatory mediators, cell survival, differentiation, apoptosis, or necrosis. ${ }^{45}$

However, soon after the use of anti-TNF-alpha antibodies in IBD (and the fact that anti-TNFR antibodies were ineffective in IBD) it appeared that they do not act only by neutralizing TNF-alpha. ${ }^{46}$ Infliximab and adalimumab have also been demonstrated to induce monocyte and T-cell apoptosis, ${ }^{47-49}$ antibody-dependent cell-mediated cytotoxicity, and complement-dependent cytotoxicity. ${ }^{50-52}$ However, it is not certain if these properties are essential for anti-TNF-alpha antibody effects as certolizumab pegol does not induce these effects despite being effective for treating IBD. Recently, it has been suggested that besides neutralizing TNF-alpha, all three anti-TNF-alpha antibodies currently being used may also act by binding to Fc-receptors, thereby inducing the formation of a specific subset of macrophages exhibiting immunosuppressive capacities such as the production of anti-inflammatory cytokines or the inhibition of T-cell proliferation. ${ }^{53,54}$

\section{Anti-TNF-alpha antibody efficacy in luminal $C D$}

The first demonstration of the clinical efficacy of anti-TNFalpha antibodies was provided in luminal CD by Targan et al who used a chimeric monoclonal anti-TNF-alpha antibody (cA2, also named infliximab or Remicade ${ }^{\circledR}$, Centocor Ortho Biotech, Inc, Horsham, PA, USA). ${ }^{21}$ The antibody was a chimeric complement-fixing immunoglobulin IgG1 composed of $25 \%$ murine-derived variable region and $75 \%$ human constant region. ${ }^{21}$ This multicenter, double-blinded, randomized, placebo-controlled trial (RCT: randomized controlled trial) enrolled $108 \mathrm{CD}$ patients with moderate to severe predominantly luminal disease (mean Crohn's disease activity index [CDAI] of approximately 300 in all four study groups). The trial showed that 4 weeks after a single infliximab infusion, $81 \%$ of patients receiving a $5 \mathrm{mg} / \mathrm{kg}$ dose had a clinical response (ie, remission when CDAI was lower than 150, or had a response when CDAI decreased by more than 70 points when compared to the baseline CDAI) in comparison to $50 \%, 64 \%$, and $17 \%$ of patients receiving $10 \mathrm{mg} / \mathrm{kg}, 20 \mathrm{mg} / \mathrm{kg}$, or placebo, respectively (Table 1). ${ }^{21}$ After 
Table I Summarized results of the major randomized controlled trials concerning efficacy of anti-tumor necrosis factor-alpha antibodies in luminal Crohn's disease

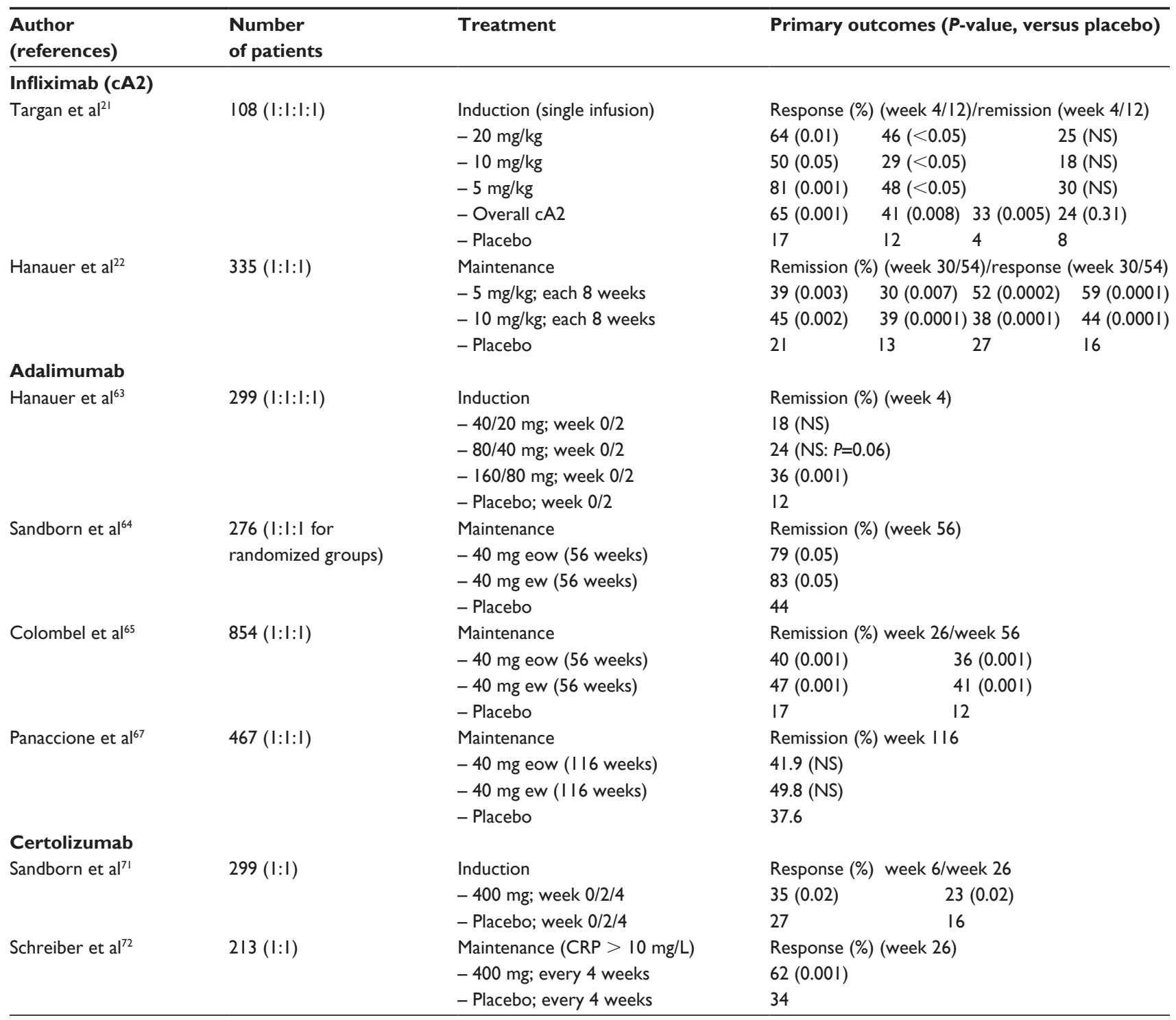

Abbreviations: eow, every other week; ew, every week; NS, not significant; CRP, C-reactive protein.

this induction study, infliximab's efficacy as a maintenance treatment in luminal CD was demonstrated in the ACCENT (A Crohn's Disease Clinical Trial Evaluating Infliximab in a New Long-term Treatment Regimen) 1 trial (Table 1). ${ }^{22}$ These results have also been confirmed in several reports of infliximab use in clinically relevant settings. ${ }^{55-57}$ For example, Schnitzler et al published results of long-term infliximab treatment in a single center cohort of $614 \mathrm{CD}$ patients (mean follow-up period of 55 months). ${ }^{57}$ They found that $63.4 \%$ of patients on maintenance treatment had sustained remission or clinical response; $68.3 \%$ of these patients were still being treated with infliximab at the end of the reported study period. Nearly $11 \%(10.9 \%)$ of patients were initially nonresponders, and treatment needed to be stopped in $12.8 \%$ of patients due to side effects and in $21.6 \%$ of patients due to loss of response. ${ }^{57}$ They also confirmed that episodic treatment, when compared to scheduled treatment, did not affect the annual dropout rate (in their experience), that less patients on scheduled treatment needed hospitalization or surgery, and that steroid withdrawal was possible in a higher proportion of patients on scheduled treatment. In our own experience with $58 \mathrm{CD}$ patients receiving induction therapy $(5 \mathrm{mg} / \mathrm{kg}$ of body weight at weeks 0,2 , and 6 ) followed by maintenance treatment every 8 weeks if they were responders at the end of the data collection (week 54), 65.5\% were in remission, $5.2 \%$ had a clinical response, and the remaining $29.3 \%$ were considered as treatment failures. ${ }^{58}$ There was no statistically significant difference between fistulizing- $(n=29)$ or 
luminal-predominant $(\mathrm{n}=29) \mathrm{CD}$ patients. Steroid withdrawal was possible in $87.5 \%$ of patients. Patients treated for persistent fistula without concomitant luminal active disease were the best responders. No other factor studied was associated with efficacy. Fifty percent of patients had at least one adverse event, and these were mostly infectious or dermatological side effects. ${ }^{59}$ Recently, comparable results have been reported by Sparkes et al. ${ }^{60}$ The usefulness of concomitant immunosuppressive therapy at the time of infliximab induction treatment to decrease immune-allergic side effects or to increase therapeutic efficacy has been questioned in several substudies and retrospective studies. Recently, the SONIC (Study of Biologic and Immunomodulator Naïve Patients in Crohn's Disease) study compared the efficacy and safety of combination therapy, infliximab alone, and AZA alone. ${ }^{61}$ It is important to note that only CD patients who had not been previously treated by either immunosuppressive or biologic therapy (treatment "naïve" patients) were enrolled. Patients receiving combination therapy (infliximab at $5 \mathrm{mg} / \mathrm{kg}$ of body weight for the induction and maintenance scheme, and AZA at $2.5 \mathrm{mg} / \mathrm{kg}$ of body weight daily) were more frequently in steroid-free remission at week 26 (the primary endpoint) than those treated with infliximab alone $(P=0.02)$ or AZA alone $(P<0.001)$ (56.8\% versus $44.4 \%$ versus $30.0 \%$, respectively). In addition, infliximab alone was significantly more effective than AZA alone $(P=0.006) .{ }^{61}$ Similar trends were observed at week $50 .{ }^{61}$ However, these results raised the question of the optimal duration for combination therapy, especially with respect to the severe life threatening (although rare) hepatosplenic lymphomas reported in CD patients on infliximab-AZA combination treatment (see section on "Safety [and side effects] of anti-TNF-alpha therapy") ${ }^{62}$

Adalimumab (Humira ${ }^{\circledR}$, Abbvie, Inc, Chicago, IL, USA) is a fully humanized human anti-TNF-alpha IgG1 monoclonal antibody. In contrast to infliximab, it is administered subcutaneously. Because it does not contain mouse peptides, it is expected that patients are less likely to develop antibodies against adalimumab and as a consequence, will present with less hypersensitivity reactions (see section on "Safety [and side effects] of anti-TNF-alpha therapy") and loss of response due to neutralization of the therapeutic antibody. The CLASSIC (Clinical Assessment of Adalimumab Safety and Efficacy Studied as Induction Therapy in Crohn's Disease) 1 study, a RCT therapeutic trial, has demonstrated adalimumab's efficacy in moderate to severe anti-TNF-alpha antibody naïve CD patients. ${ }^{63}$ Patients $(n=299)$ with moderate to severe CD were assigned to receive a 4-week induction treatment with either adalimumab at $40 \mathrm{mg}$ at week 0 and $20 \mathrm{mg}$ at week 2 , adalimumab $80 \mathrm{mg} / 40 \mathrm{mg}, 160 \mathrm{mg} / 80 \mathrm{mg}$, or placebo. The primary endpoint, clinical remission $(\mathrm{CDAI}<150)$ at week 4 , was achieved in $18 \%$ (not significantly different versus placebo at $12 \%)$, in $24 \%(P=0.06$, not significantly different versus placebo), and in $36 \%$ ( $P=0.001$ versus placebo) of patients, respectively, with response rates of $37 \%$ for the $80 \mathrm{mg} / 40 \mathrm{mg}$ dose and of $49 \%$ for the $160 \mathrm{mg} / 80 \mathrm{mg}$ dose (compared with $23 \%$ in the placebo group) (Table 1). ${ }^{63}$ The CLASSIC I study was followed by the CLASSIC II trial which included patients in remission at week 4 in the CLASSIC I cohort. They received open-label $40 \mathrm{mg}$ adalimumab for 4 weeks before randomization to receive maintenance treatment of $40 \mathrm{mg}$ adalimumab every other week (eow), $40 \mathrm{mg}$ adalimumab every week, or placebo for 56 weeks. ${ }^{64}$ Remission rates and clinical response rates were significantly higher in both active arms when compared to placebo (remission rates: $40 \mathrm{mg}$ eow $=79 \%, 40 \mathrm{mg}$ weekly $=83 \%$, placebo $=44 \%, P<0.05)($ Table 1$) .{ }^{64}$ These results were confirmed in the CHARM (Crohn's Trial of the Fully Human Antibody Adalimumab for Remission Maintenance) trial, a large scale Phase III trial $(n=854) .{ }^{65}$ After an open-label induction treatment of adalimumab $80 \mathrm{mg}$ followed by $40 \mathrm{mg} 2$ weeks later, patients were randomized in the same manner as the CLASSIC 2 study. Additionally, patients who presented a CD flare-up at week 12 could switch to an openlabel $40 \mathrm{mg}$ eow adalimumab treatment. Remission rates were significantly higher in both active arms at weeks 26 and 56 (36\% and $41 \%$, respectively, versus $12 \%$ in placebo-treated patients at week 56, $P<0.001$ ) with no statistically significant difference between adalimumab administered at $40 \mathrm{mg}$ eow and $40 \mathrm{mg}$ weekly for maintenance treatment (Table 1). ${ }^{65}$ Neither previous anti-TNF-alpha therapy with concomitant immunosuppressive treatment or baseline $\mathrm{C}$-reactive protein (CRP) concentration affected remission rates, response rates, or steroid-free clinical remission (29\% for adalimumab $40 \mathrm{mg}$ eow at week 56 versus $23 \%$ for weekly treatment versus $3 \%$ in the placebo group, at week $56 P<0.001$ only for adalimumab eow). ${ }^{65}$ The GAIN (Gauging Adalimumab efficacy in Infliximab Nonresponders) study also reported that a proportion of patients who previously lost response to infliximab, or who had stopped infliximab due to unacceptable side effects, responded to adalimumab. ${ }^{6}$ Following the CHARM trial, 467 patients who successfully completed the trial, entered the ADHERE (Additional long-term Dosing with Humira to Evaluate sustained remission and Efficacy in Crohn's disease) study, an open-label extension of maintenance treatment. Those from the blinded groups were treated with adalimumab administered at $40 \mathrm{mg}$ eow, and those who changed to an open-label treatment with adalimumab administered at either $40 \mathrm{mg}$ eow or $40 \mathrm{mg}$ 
weekly during the CHARM study continued their previous adalimumab administration schedule (eow or weekly). ${ }^{67}$ After a treatment period of up to 2 years, $41.9 \%, 49.8 \%$ and $37.6 \%$ of patients who were initially randomly assigned to receive a maintenance treatment of adalimumab administered at $40 \mathrm{mg}$ eow, $40 \mathrm{mg}$ weekly, or placebo, remained in clinical remission with a sustained improvement in quality of life for all three groups as measured by the Inflammatory Bowel Disease Questionnaire. ${ }^{67}$ As reported for infliximab in the SONIC study, a recently published retrospective study performed in Oxford (UK) and Liège (Belgium) reported that adalimumab combined with immunosuppressive therapy during the first semester of treatment slightly improved adalimumab's efficacy ( $5 \%$ versus $10 \%, P=0.04$, odds ratio of 0.48 ), fewer semesters with flareups ( $14 \%$ versus $36 \%, P=0.02$, odds ratio of 0.31$)$, and a lower need for dosage escalation during maintenance therapy. ${ }^{68}$

The third anti-TNF-alpha antibody which can be prescribed in several countries for CD treatment is certolizumab pegol (CDP870 or Cimzia ${ }^{\circledR}$, UCB S.A., Brussels, Belgium), a polyethylene-glycosylated (PEG) Fab' fragment of a humanized anti-TNF-alpha monoclonal antibody. The addition of PEG increased the antibody half-life (which is normally less for the Fab' fragment when compared to the whole antibody) and decreased its distribution volume and clearance. ${ }^{69}$ Following an encouraging but mitigated Phase II placebo-controlled, randomized, dose-finding study, ${ }^{70}$ two Phase III trials (PRECiSE [Pegylated Antibody Fragment Evaluation in Crohn's Disease: Safety and Efficacy] 1 and PRECiSE 2) demonstrated its efficacy in luminal $C D$ both as induction and maintenance treatments. ${ }^{71,72}$ In the PRECiSE 1 study, patients received either induction therapy with $400 \mathrm{mg}$ certolizumab pegol (subcutaneous injection) at weeks 0,2 , and $4(n=329)$ or placebo $(n=331)$, followed by maintenance therapy of $400 \mathrm{mg}$ every 4 weeks from week 8 to $26 .{ }^{71}$ Although remission rates did not differ at weeks 6 and 26, clinical response (100 points less than baseline CDAI, the primary endpoint of the study) was significantly higher in the treated group at both time points $(23 \%$ versus $16 \%$ at the two points of measurement, $P=0.02$ ) (Table 1$).{ }^{71}$ In the PRECiSE 2 trial, both the treated and placebo groups received an open-label induction treatment (the same induction scheme as in PRECiSE 1) with a remission rate of 43\% (289 from 668 patients) and a response rate (100 points less than baseline CDAI) of $64 \%$ (428 of 668 patients) (Table 1). ${ }^{72}$ Following this open-label induction phase, only patients who achieved clinical response were randomized to receive either maintenance treatment (400 mg certolizumab pegol every 4 weeks) or placebo until week 26. In intention-to-treat analysis, response rates were $63 \%$ and $36 \%$, respectively $(P<0.001)$, and remission rates were $48 \%$ and $29 \%$, respectively $(P<0.001) .{ }^{72}$ In both the PRECiSE 1 and 2 studies, patients with a baseline CRP blood concentration $\geq 10 \mathrm{mg} / \mathrm{L}$ showed higher response and remission rates. A subanalysis of PRECiSE 2 results does not show a better response to certolizumab pegol in those patients on immunosuppressive therapy at inclusion compared to those naïve of immunosuppressants. ${ }^{72}$ These results on long-term efficacy were confirmed in the PRECiSE 3 study for 18 months of treatment with certolizumab pegol. ${ }^{73}$

Studies comparing the three monoclonal anti-TNF-alpha antibodies directly are not available (and probably will never be performed). However, a meta-analysis by Peyrin-Biroulet et al does not show any difference between these three antibodies for induction and maintenance treatment of luminal CD. ${ }^{74}$

\section{Anti-TNF-alpha antibody efficacy in fistulizing $C D$}

Fistulizing $\mathrm{CD}$ often requires multimodal combined medical and surgical treatment, as surgical treatment alone has shown its limitations and potential dangers. ${ }^{75}$ The first evidence for anti-TNF-alpha monoclonal antibody efficacy for CD fistula treatment was demonstrated both for induction and maintenance treatment using infliximab. ${ }^{23}$

In 1999, Present et al reported, in an RCT, a reduction of more than $50 \%$ in draining fistulas during at least two consecutive study visits in $68 \%$ and $56 \%$ of the 94 participating CD patients, with draining abdominal or perianal fistulas of at least 3 months duration, receiving either a $5 \mathrm{mg} / \mathrm{kg}$ of body weight $(\mathrm{n}=31)$ or a $10 \mathrm{mg} / \mathrm{kg}$ of body weight $(\mathrm{n}=32)$ induction treatment with infliximab (infusion at week 0,2 , and 6). ${ }^{23}$ This reduction was statistically significant when compared with the placebo group $(\mathrm{n}=26)$ with $P$-values of 0.002 and 0.02 , respectively (Table 2 ). ${ }^{23}$ The second endpoint (complete closure of all draining fistulas) was achieved in $55 \%$ and $38 \%$ of treated patients when compared with $13 \%$ of patients receiving placebo ( $P=0.001$ and 0.04 , respectively) (Table 2). ${ }^{23}$ This induction trial was followed by a maintenance study showing that at week $54,36 \%$ of patients receiving $5 \mathrm{mg} / \mathrm{kg}$ of infliximab every 8 weeks following an induction treatment had complete closure of all draining abdominal or perianal fistulas, compared with $19 \%$ of the placebo group $(P=0.009)$ (Table 2). ${ }^{24}$ In addition, the time to loss of response was shown to be significantly longer in treated patients $(>40$ weeks versus 14 weeks, $P<0.001$ ) (Table 2$).{ }^{24}$ It is important to note that more than $85 \%$ of patients in both the induction and maintenance trials had perianal fistula; this means that the results of these studies can probably not be strictly extrapolated to enterocutaneous (abdominal) or rectovaginal fistulas. 
Table 2 Summarized results of the major randomized controlled trials concerning efficacy of anti-tumor necrosis factor-alpha antibodies in fistulizing Crohn's disease

\begin{tabular}{|c|c|c|c|c|}
\hline $\begin{array}{l}\text { Author } \\
\text { (reference) }\end{array}$ & $\begin{array}{l}\text { Number } \\
\text { of patients }\end{array}$ & Treatment & \multicolumn{2}{|c|}{ Primary outcomes ( $P$-value, versus placebo) } \\
\hline \multicolumn{5}{|l|}{ Infliximab } \\
\hline \multirow[t]{5}{*}{ Present et $\mathrm{a}^{23}$} & $94(1: 1: 1)$ & Induction (week 0/2/6) & \multicolumn{2}{|c|}{$\begin{array}{l}\text { Response (\%): decrease of } \geq 50 \% \text { draining fistulas } \\
\text { at } \geq 2 \text { consecutive visits }\end{array}$} \\
\hline & & $-10 \mathrm{mg} / \mathrm{kg}$ & \multicolumn{2}{|l|}{$56(0.02)$} \\
\hline & & $-5 \mathrm{mg} / \mathrm{kg}$ & \multicolumn{2}{|l|}{$68(0.002)$} \\
\hline & & - Overall cA2 & \multicolumn{2}{|l|}{$62(0.002)$} \\
\hline & & - Placebo & \multicolumn{2}{|l|}{26} \\
\hline \multirow[t]{3}{*}{ Sands et a ${ }^{24}$} & $282(1: 1)$ & Maintenance & \multicolumn{2}{|c|}{ Time to loss of response/complete closure (week 54) } \\
\hline & & $-5 \mathrm{mg} / \mathrm{kg}$; each 8 weeks & $>40$ weeks $(0.001)$ & $36(0.009)$ \\
\hline & & - Placebo & 14 & 19 \\
\hline \multicolumn{5}{|l|}{ Adalimumab } \\
\hline \multirow[t]{11}{*}{ Colombel et $\mathrm{al}^{78}$} & $117(1: 1: 1)$ & Maintenance & \multirow{3}{*}{\multicolumn{2}{|c|}{ Complete fistula closure (\%) (week 56) }} \\
\hline & of responders & After open-label induction & & \\
\hline & 4 weeks after & $80 / 40 \mathrm{mg} ;$ week $0 / 2$ & & \\
\hline & induction & $-40 \mathrm{mg}$ eow & \multicolumn{2}{|c|}{ Results for both adalimumab groups } \\
\hline & & $-40 \mathrm{mg}$ ew & \multicolumn{2}{|l|}{$33(0.05)$} \\
\hline & & - Placebo eow & \multicolumn{2}{|l|}{13} \\
\hline & & & \multicolumn{2}{|c|}{ Mean number of draining fistula } \\
\hline & & $-40 \mathrm{mg}$ eow & \multicolumn{2}{|l|}{0.85} \\
\hline & & $-40 \mathrm{mg} \mathrm{ew}$ & \multicolumn{2}{|l|}{0.91} \\
\hline & & - Both adalimumab groups & \multicolumn{2}{|l|}{$0.88(0.002)$} \\
\hline & & - Placebo & \multicolumn{2}{|l|}{1.34} \\
\hline \multicolumn{5}{|l|}{ Certolizumab } \\
\hline \multirow[t]{6}{*}{ Schreiber et al ${ }^{80}$} & $58(I: I)$ & Maintenance & \multirow{3}{*}{\multicolumn{2}{|c|}{$\begin{array}{l}\text { Response I (\%): protocol-defined fistula closure } \\
\text { and } \geq 50 \% \text { draining fistulas at } 2 \text { consecutive post-baseline } \\
\text { visits } \geq 3 \text { weeks apart (week } 26 \text { ) }\end{array}$}} \\
\hline & of responders & After open-label induction & & \\
\hline & 6 weeks after & 400 mg eow $(0 / 2 / 4)$ & & \\
\hline & induction & & \multicolumn{2}{|c|}{$\begin{array}{l}\text { Response } 2(\%) \text { : protocol-defined fistula closure } \\
\text { and 100\% fistula closure (week } 26 \text { ) }\end{array}$} \\
\hline & & - 400 mg; each 4 weeks & \multicolumn{2}{|l|}{$54(\mathrm{NS}) / 36(0.038)$} \\
\hline & & - Placebo; each 4 weeks & \multicolumn{2}{|l|}{$43 / 17$} \\
\hline
\end{tabular}

Notes: eow, every other week; ew, every week; NS, not significant.

To our knowledge, except for several case reports, only one study has retrospectively addressed the question of infliximab's efficacy in enterocutaneous fistula closure. ${ }^{76}$ The outcome of 42 patients treated with infliximab $(n=38)$, adalimumab $(n=1)$, or infliximab followed by adalimumab $(n=3)$ for spontaneous $(n=24)$ or postoperative $(n=18)$ fistulas (small bowel: $n=21$, ileocolonic anastomosis: $\mathrm{n}=15$, duodenum: $\mathrm{n}=1$, and colon: $\mathrm{n}=1$ ) were analyzed. Complete closure was observed in $38 \%$ of patients with a median time to closure of 83 days. ${ }^{76}$ Results were better in spontaneous and in simple fistulas. ${ }^{76}$ Finally, it is important to mention that exposure to infliximab (in patients with no abscess at the time treatment was started) does not significantly increase the risk of abscess development over time in fistulizing CD patients. ${ }^{77}$

Specific data concerning fistula closure in patients treated with adalimumab are not available. Therefore, its effect in perianal CD can only be assessed by post hoc analysis. The post hoc analysis of the CHARM study has shown that adalimumab reduced the average number of draining fistulas per day after 56 weeks of treatment ( 0.88 versus 1.34 draining fistulas per day in the adalimumab and the placebo groups, respectively, $P<0.002$ ) (Table 2$).{ }^{78}$ Most of the patients who had closed fistulas at the end of this period $(90 \%)$ maintained closure after open-label additional adalimumab treatment for 1 year (Table 2). ${ }^{78}$ Additional information was gained from the open-label single arm CHOICE (Crohn's disease wHO failed prior Infliximab to Collect safety data and Efficacy via patient-reported outcome measures) trial. ${ }^{79}$ It enrolled patients failing infliximab therapy. The patients received a 160/80 $\mathrm{mg}$ induction treatment followed by a $40 \mathrm{mg}$ eow maintenance treatment of adalimumab. Among the 88 patients having at least one draining fistula at adalimumab initiation, complete fistula healing was possible in 34 patients (39\%). ${ }^{79}$ However, the follow-up duration was too short (maximum 36 weeks) to conclude that the benefit was long-term. ${ }^{79}$ This improvement in perianal disease also has an impact on quality of life and the ability to work normally was sustained until week 24 in all patients. ${ }^{80}$ 
The PRECiSE 3 study examined the effects of certolizumab pegol on fistula healing among patients having draining fistula(s) when they entered the PRECiSE 2 trial. At week $26,36 \%$ of the patients from the treatment group had complete fistula closure compared to $17 \%$ from the placebo group ( $P=0.038)$ (Table 2). Again, data on the long-term effect on fistulas closure (at least 12 months) are not available at this time. ${ }^{80}$

\section{Anti-TNF-alpha antibody efficacy in UC}

The efficacy of infliximab to induce and maintain clinical response or remission in UC has been demonstrated in two RCTs (the Active Ulcerative Colitis Trials 1 and 2 [ACT 1 and the ACT 2] studies) published in $2005 .{ }^{25}$ Patients with moderate to severe UC $(n=364$ in each trial) received an induction treatment followed by a maintenance treatment until week 46 (end of follow-up was week 54) or week 22 (end of follow-up was week 30) in the ACT 1 and ACT 2 studies, respectively. Considering the induction treatment, $69.4 \%$ of patients receiving $5 \mathrm{mg} / \mathrm{kg}$ of infliximab and $61.5 \%$ of patients receiving infliximab at $10 \mathrm{mg} / \mathrm{kg}$ achieved clinical response at week 8 in the ACT 1 study (versus $37.2 \%$ in the placebo group, $P<0.001$ ) (Table 3 ). In the ACT 2 study, the response rates at week 8 were $64.5 \%(5 \mathrm{mg} / \mathrm{kg}$ infliximab), $69.2 \%$ (10 $\mathrm{mg} / \mathrm{kg}$ infliximab), and $29.3 \%$ (placebo group) $(P<0.001$ versus the placebo group) (Table 3$) .{ }^{25}$ Clinical

Table 3 Summarized results of the major randomized controlled trials concerning efficacy of anti-tumor necrosis factor-alpha antibodies in ulcerative colitis treatment

\begin{tabular}{|c|c|c|c|c|c|c|}
\hline \multirow{2}{*}{$\begin{array}{l}\begin{array}{l}\text { Author } \\
\text { (reference) }\end{array} \\
\text { Infliximab }\end{array}$} & \multirow[t]{2}{*}{$\begin{array}{l}\text { Number } \\
\text { of patients }\end{array}$} & \multirow[t]{2}{*}{ Treatment } & \multicolumn{4}{|c|}{ Primary outcomes ( $P$-value, versus placebo) } \\
\hline & & & & & & \\
\hline \multicolumn{7}{|l|}{ Rutgeerts et a ${ }^{25}$} \\
\hline \multirow[t]{12}{*}{ ACT I } & \multirow[t]{12}{*}{$364(1: 1: 1)$} & Induction (week 0/2/6) & \\
\hline & & $-10 \mathrm{mg} / \mathrm{kg}$ & \multicolumn{4}{|c|}{$\begin{array}{l}\text { Response }(\%) * / \text { remission }{ }^{\# / m u c o s a l ~ h e a l i n g ~}{ }^{\#}(\text { week } 8) \\
61.5(<0.001) \quad 32.0(0.002) \quad 59.0(<0.001)\end{array}$} \\
\hline & & $-5 \mathrm{mg} / \mathrm{kg}$ & $69.4(<0.001)$ & $38.8(<0.001)$ & \multicolumn{2}{|l|}{$62.0(<0.001)$} \\
\hline & & - Placebo & 37.2 & 14.9 & \multicolumn{2}{|l|}{33.9} \\
\hline & & Maintenance & \multicolumn{4}{|c|}{ Response (\%) (week 30/54)/remission ${ }^{\#}$ (week 30/54) } \\
\hline & & - $10 \mathrm{mg} / \mathrm{kg}$; each 8 weeks & $50.8(0.002)$ & $44.3(<0.001)$ & $36.9(<0.001)$ & $34.4(0.001)$ \\
\hline & & $-5 \mathrm{mg} / \mathrm{kg}$; each 8 weeks & $52.1(<0.001)$ & $45.5(<0.001)$ & $33.9(0.001)$ & $34.7(0.001)$ \\
\hline & & - Placebo & 29.8 & 19.8 & 15.7 & 16.5 \\
\hline & & & \multicolumn{4}{|c|}{ Mucosal healing ${ }^{\#}$ week 30/54)/response ${ }^{\#}$ woc (week 30/54) } \\
\hline & & $-10 \mathrm{mg} / \mathrm{kg}$; each 8 weeks & $49.2(<0.00 \mathrm{I})$ & $46.7(<0.001)$ & 19.2 (NS) It & 6.4 (NS) \\
\hline & & $-5 \mathrm{mg} / \mathrm{kg}$; each 8 weeks & $50.4(<0.001)$ & $45.5(<0.001)$ & $24.3(0.030) \quad 2$ & $25.7(0.006)$ \\
\hline & & - Placebo & 24.8 & 18.2 & 10.1 & 3.9 \\
\hline \multirow[t]{12}{*}{ АCT 2} & \multirow{12}{*}{$364(1: 1: 1)$} & Induction (week 0/2/6) & \multicolumn{4}{|c|}{ Response (\%)*/remission"/mucosal healing" (week 8) } \\
\hline & & $-10 \mathrm{mg} / \mathrm{kg}$ & $69.2(<0.00 \mathrm{I})$ & $27.5(<0.00 \mathrm{I})$ & \multicolumn{2}{|c|}{$61.7(<0.001)$} \\
\hline & & $-5 \mathrm{mg} / \mathrm{kg}$ & $64.5(<0.00 \mathrm{I})$ & $33.9(<0.001)$ & \multicolumn{2}{|l|}{$60.3(<0.001)$} \\
\hline & & - Placebo & 29.3 & 5.9 & \multicolumn{2}{|l|}{30.9} \\
\hline & & Maintenance & \multicolumn{4}{|c|}{ Response $^{\#}$ (week 30)/remission" ${ }^{\#}$ week 30) } \\
\hline & & $-10 \mathrm{mg} / \mathrm{kg}$; each 8 weeks & $60.0(<0.00 \mathrm{I})$ & \multicolumn{3}{|l|}{$35.8(<0.001)$} \\
\hline & & $-5 \mathrm{mg} / \mathrm{kg}$; each 8 weeks & $47.1(<0.001)$ & \multicolumn{3}{|l|}{$25.6(0.003)$} \\
\hline & & - Placebo & 26 & \multicolumn{3}{|l|}{10.6} \\
\hline & & Maintenance (continued) & \multicolumn{4}{|c|}{ Mucosal healing (week 30)/response ${ }^{\#}$ woc (week 30) } \\
\hline & & - 10 mg/kg; each 8 weeks & $56.7(<0.00 \mathrm{I})$ & \multicolumn{3}{|l|}{$27.3(<0.001)$} \\
\hline & & $-5 \mathrm{mg} / \mathrm{kg}$; each 8 weeks & $46.3(0.009)$ & \multicolumn{3}{|l|}{$18.3(0.010)$} \\
\hline & & - Placebo & 30.1 & \multicolumn{3}{|l|}{3.3} \\
\hline Adalimumab & & & & & & \\
\hline Reinisch et $\mathrm{al}^{88}$ & $390(1: 1: 1)$ & Induction & Remission (\%)* & /response $\# /$ muco & sal healing" (wee & ek 8) \\
\hline & & - I60/80/40 mg; week 0/2/4 & $18.5(0.031)$ & 54.6 (NS) & 46.9 (NS) & \\
\hline & & - 80/40/40 mg; week 0/2/4 & $10(\mathrm{NS})$ & 51.5 (NS) & 37.7 (NS) & \\
\hline & & - Placebo; week 0/2/4 & 9.2 & 44.6 & 41.5 & \\
\hline Sandborn et al ${ }^{91}$ & $276(I: I)$ & Induction & Remission (\%)* & response*/mucc & sal healing* (we & ek 8) \\
\hline & & - I60/80/40 mg; week 0/2/4 & $16.5(<0.05)$ & $50.4(<0.005)$ & $4 \mathrm{I} . \mathrm{I}(<0.05)$ & \\
\hline & & - Placebo; week 0/2/4 & 9.3 & 34.6 & 31.7 & \\
\hline & & Maintenance & Remission (\%)* & response*/mucc & sal healing* (we & ek 52) \\
\hline & & - $40 \mathrm{mg}$ eow (56 weeks) & $17.3(<0.005)$ & $30.2(<0.05)$ & $25.0(<0.05)$ & \\
\hline & & - Placebo; week 0/2/4 & 8.5 & 18.3 & 15.4 & \\
\hline
\end{tabular}

Note: *primary end point; \# secondary end point.

Abbreviations: eow, every other week; NS, not significant; woc, without corticosteroids; ACT, Active Ulcerative Colitis Trial. 
response was defined as a decrease of at least three points in the global Mayo score, with a decrease of at least one point in the subscore for rectal bleeding, or an absolute rectal bleeding subscore of one or zero. At week 30, patients receiving infliximab (in both trials) more frequently had a prolonged clinical response ( $P \leq 0.002$ ), and in the ACT 1 study, $45.5 \%$ (5 mg/kg infliximab), 44.3\% (10 mg/kg infliximab), and $19.8 \%$ (placebo group) of patients had a clinical response $(P<0.001)$ (Table 3). ${ }^{25}$ Both studies showed a maintained improvement in quality of life. ${ }^{25}$ These results were confirmed in retrospective studies on long-term follow-up in unselected UC patients treated with infliximab, ${ }^{81-83}$ with reports of a need for dose escalation to maintain clinical remission or maintenance in approximately half of the patients. ${ }^{83}$ Patients requiring dose escalation had lower sustained remission/response rates and needed colectomy more often. ${ }^{83}$ A long-term extension study of ACT 1 and ACT 2 was published in 2012, showing that for up to 3 additional years, infliximab in UC was effective and well tolerated. ${ }^{84}$ Finally, infliximab has been shown to be a valuable alternative to cyclosporine for treating acute severe UC refractory to IV steroid treatment. ${ }^{85-87}$ In a recent randomized study, Laharie et al and the GETAID (Groupe d'Etudes Thérapeutiques des Affections Inflammatoires du tube Digestif) demonstrated that cyclosporine ( $\mathrm{n}=55$ patients) is not more effective than infliximab $(n=56)$ in achieving short-term remission or avoiding colectomy in acute severe UC attacks refractory to a well-conducted IV steroid treatment scheme. ${ }^{87}$

Adalimumab has been approved for clinical use in the US and in France for the treatment of UC. Evidence of adalimumab's efficacy in UC first came from open-label or retrospective studies. Recently, two RCTs addressed the question of adalimumab's efficacy in induction and maintenance treatment in UC. ${ }^{88,91}$ Reinisch et al reported on the results of a RCT in remission induction. ${ }^{88}$ All enrolled patients $(n=186)$ were naïve to anti-TNF-alpha therapy and failed, or did not tolerate, treatment with steroids or immunomodulators. They randomly received a 160/80 mg adalimumab induction regimen, a 80/40 mg initial dose, or placebo, with clinical remission at week 8 (assessed by a full Mayo score $\leq 2$ ) as the primary endpoint. Clinical remission was observed in $18.5 \%, 10 \%$, and $9.2 \%$ of patients, respectively, with a statistically significant difference between the $160 / 80 \mathrm{mg}$ and the placebo groups $(P=0.031)$ (Table 3). ${ }^{88}$ No difference was found for clinical response but the differences for the rectal bleeding subscore $(P=0.038)$ and the physician global assessment $(P=0.035)$ were statistically significant. ${ }^{88}$ Post hoc analysis revealed that several factors predicted low remission rates: more active disease, more extended mucosal inflammation, and a baseline CRP concentration $\geq 10 \mathrm{mg} / \mathrm{mL} .{ }^{88}$ As a continuation of this induction trial, 390 patients (from all 3 study groups) were open-label treated with $40 \mathrm{mg}$ adalimumab eow beginning at week 8 , until week 52 , with the possibility of switching to $40 \mathrm{mg}$ weekly for nonresponding patients or patients presenting with a UC flare-up. At week 52, with patients necessitating dose escalation considered as treatment failures, $25.6 \%$ were in clinical remission. ${ }^{89} \mathrm{~A}$ post hoc analysis, where dose escalation as a failure was not considered, found a response rate of $29.5 \%$ at week $52 . .^{90}$ The second RCT (the ULTRA [Ulcerative colitis long-term remission and maintenance with adalimumab] 2 trial) enrolled 494 patients on concomitant oral steroids or immunosuppressive therapy and stratified patients according to prior treatment with anti-TNF-alpha antibodies. ${ }^{91}$ Patients received either $160 \mathrm{mg}$ of adalimumab at week $0,80 \mathrm{mg}$ at week 2 followed by $40 \mathrm{mg}$ eow, or placebo. At week $8,16.5 \%$ of patients in the treatment group were in clinical remission compared with $9.3 \%$ of patients in the placebo group $(P=0.019)$ (Table 3). ${ }^{91}$ At week 52 (end of the maintenance phase) overall remission rates were $17.3 \%$ and $8.5 \%$, respectively $(P=0.004)$ (Table 3). ${ }^{91}$ In anti-TNF-alpha naïve patients, remission rates were $21.3 \%$ for treated patients (versus $11 \%$ for patients on placebo, $P=0.017$ ) at week 8 and $22 \%$ versus $12.4 \%$ at week $52(P=0.029) .{ }^{91}$ In patients who had previously received antiTNF-alpha agents, the corresponding remission rates were $9.2 \%$ versus $6.9 \%(P=0.559)$ and $10.2 \%$ versus $3 \%(P=0.039)$ at week 8 and 52, respectively. ${ }^{91}$ Certolizumab pegol has not been studied in UC patients.

\section{Loss of response, dose adaptation, and switching to another anti-TNF-alpha antibody}

Despite the high clinical response rates, loss of response or occurrence of adverse effects not compatible with treatment maintenance develops in a substantial number of patients.

Table 4 Recommended treatment regimens of anti-tumor necrosis factor-alpha antibodies in inflammatory bowel disease patients

\begin{tabular}{|c|c|c|}
\hline $\begin{array}{l}\text { Antibody } \\
\text { (brand name) }\end{array}$ & Induction treatment & $\begin{array}{l}\text { Maintenance } \\
\text { treatment }\end{array}$ \\
\hline $\begin{array}{l}\text { Infliximab } \\
\text { (Remicade }^{\circledR} \text { ) }\end{array}$ & $\begin{array}{l}\text { Intravenous infusion (IV): } \\
5 \mathrm{mg} / \mathrm{kg} \text { body weight (BW) } \\
\text { at week (w) } 0,2 \text { and } 6\end{array}$ & $\begin{array}{l}5 \mathrm{mg} / \mathrm{kg} \text { BW IV } \\
\text { each } 8 \text { weeks }\end{array}$ \\
\hline $\begin{array}{l}\text { Adalimumab } \\
\left(\text { Humira }^{\circledR}\right)\end{array}$ & $\begin{array}{l}\text { Subcutaneous injection (SC): } \\
160 \mathrm{mg} \text { (w0), } 80 \mathrm{mg}(\mathrm{w} 2) \\
40 \mathrm{mg} \text { (w4) }\end{array}$ & $\begin{array}{l}40 \mathrm{mg} \mathrm{SC} \text { every } \\
2 \text { weeks }\end{array}$ \\
\hline $\begin{array}{l}\text { Certolizumab } \\
\left.\text { pegol (Cimzia }{ }^{\circledR}\right)\end{array}$ & $400 \mathrm{mg} \mathrm{SC}$ at w0, 2 and 4 & $\begin{array}{l}400 \mathrm{mg} \text { SC every } \\
4 \text { weeks }\end{array}$ \\
\hline
\end{tabular}


In order to standardize the concept of loss of response, it is important to distinguish it from primary nonresponse. For infliximab, primary nonresponse can be defined as the absence of clinical improvement following the first 8-week interval in patients who received a classical induction scheme (Table 4). For adalimumab, primary nonresponse is defined by the absence of response at the first $40 \mathrm{mg}$ injection following a 160/80/40 mg induction regimen (Table 4).

Definition of loss of response per se remains controversial and has been recently detailed and discussed by Ben-Horin and Chowers. ${ }^{92}$ They proposed mechanisms responsible for loss of response including non-inflammatory mechanisms (eg, obstructive fibrostenotic strictures during anti-TNF-alpha treatment needing surgery), loss of anti-TNF-alpha activity due to antidrug antibodies, and uncontrolled IBD flare-up despite adequate anti-TNF-alpha treatment. ${ }^{92}$ Several strategies have been proposed to avoid, or at least to delay, the time to loss of response. For infliximab, it has been shown that a scheduled treatment with a long-term maintenance period is more effective than episodic treatment, and that this elicits less immunogenicity and decreases the need for hospitalization or surgery. ${ }^{93,94}$ The role of steroids to decrease anaphylactic episodes has not been clearly proven although steroids seem to be able to reduce immunogenicity. ${ }^{95}$ In contrast, concomitant immunosuppression, at least at the beginning of infliximab treatment, has been suggested to reduce the formation of antibodies to infliximab (ATI) and to increase the time of maintenance of clinical benefit. ${ }^{95,96}$ Additionally, and as stated earlier, the recent SONIC trial had shown significantly better and sustained remission/response rates in patients treated with the combined infliximab/AZA regimen. ${ }^{61}$ It is important to note (see also "Conclusion and future developments") that at week $26,43.9 \%$ of patients on combination therapy achieved mucosal healing, compared with $30.1 \%$ in the infliximab group $(P=0.06$ versus combination therapy), and with $16.5 \%$ in the AZA group $(P<0.001$ and $P=0.02$, respectively, versus the two other groups). ${ }^{96}$

Because they are human or humanized monoclonal antibodies respectively, adalimumab and certolizumab pegol are suggested to be less immunogenic than infliximab. Nevertheless, in adalimumab-treated patients a comparable loss of response in comparison to infliximab-treated IBD patients was observed, ${ }^{91}$ and combination with an immunosuppressor during the first semester has also been suggested to slightly reduce the risk for early loss of response. ${ }^{68}$ In cases of loss of response, currently in standard clinical practice, there are several strategies to regain response before switching to another anti-TNF-alpha antibody or changing treatment.
For infliximab, there are two theoretical options: dose intensification or interval reduction between two infusions. For adalimumab, dose escalation is not usually recommended but reducing the frequency of injections from $40 \mathrm{mg}$ adalimumab eow to every week is often suggested. Several studies have shown that dose intensification results in a regained response in $50 \%$ to $70 \%$ of treated patients..$^{91}$ Usually, for infliximab, the choice between increasing dose or reducing infusion interval depends on the type of loss of response. For patients describing an effect of infliximab over several (4 to 7) weeks following a maintenance infusion before reappearance of disease symptoms and worsening of their quality of life one or several weeks before the next scheduled infusion, the first step seems, in our opinion, to be a decrease of infusion interval without changing the dose. In contrast, if the response to a maintenance infliximab infusion does not significantly improve symptoms during the 4 weeks following the infusion, we have found it more relevant to increase the dose to $7.5 \mathrm{mg} / \mathrm{kg}$, or to $10 \mathrm{mg} / \mathrm{kg}$. In some cases there is a need to combine dose escalation with reduction of infusion interval. However, these strategies are only a result of clinical experience and there are only preliminary data to support their relevance. ${ }^{97,98}$ More objective and fine-tuned strategies are needed, and will probably be developed in the coming years as several trials are ongoing, or close to being started, to better manage anti-TNF-alpha treatment in the long-term in general, and in cases of loss of response in particular.

In cases of failure of dose adaptation, switching to another anti-TNF-alpha monoclonal antibody is possible and has been reported in several RCTs or open cohort studies. The GAIN study reported the first results of switching infliximab nonresponsive CD patients to adalimumab. ${ }^{66}$ Patients were considered as having loss of response if they had been treated with at least two infliximab infusions with an initial response but a secondary lack of clinical benefit, or if their clinical status worsened at least 2 weeks after the second infliximab infusion. Patients intolerant to infliximab (exhibiting an acute adverse reaction or a delayed infusion reaction) were also enrolled. After 4 weeks of treatment, adalimumab (160/80 $\mathrm{mg}$ at week 0 and 2$)$ induced remission in $21 \%$ of patients compared to $7 \%$ in the placebo-treated patients $(P<0.001)$, and the percentage of patients with clinical response was also higher in the adalimumab versus the placebo group. ${ }^{66}$ After this initial randomized induction regimen, patients could enter an open-label extension to receive $40 \mathrm{mg}$ of adalimumab eow: $39 \%$ and $29 \%$ of patients were in clinical remission at 6 months and 1 year, respectively. ${ }^{99}$ A meta-analysis of open-label cohorts $(n=13)$ and RCTs 
$(n=2)$ studying the efficacy of adalimumab in infliximab primary or secondary nonresponsive patients, was published in 2009 by Ma et al. ${ }^{100}$ In nine studies, short-term clinical response at week 4 ranged from $41 \%$ to $83 \%$ of patients and long-term response (12 months, eight studies) ranged from $19 \%$ to $68 \%$ of patients. ${ }^{100}$ Currently, a definite and more precise conclusion could not be given, in particular due to the important variability in study designs, including the characteristics of the enrolled patients. Consequently, in future studies, a clear definition of primary nonresponse, intolerance, and secondary loss of response should be proposed by experts in order for data from different studies to be compared properly and provide a better idea of the real efficacy of each anti-TNFalpha monoclonal antibody used, after failure of a first (or a second) treatment using another anti-TNF-alpha antibody.

Several studies have also reported data suggesting that certolizumab pegol may be an effective treatment after a first anti-TNF-alpha monoclonal antibody treatment. A post hoc analysis of the data from the PRECiSE 2 study has shown that $44 \%$ of patients with prior infliximab therapy had a clinical benefit from second line certolizumab pegol therapy (compared with $26 \%$ in the placebo group, $P=0.018$ ). ${ }^{101} \mathrm{In}$ infliximab naïve patients, the response rate was $66 \%$ compared to $40 \%$ in the placebo group $(P<0.001)$, taking into account that these patients had a shorter $C D$ duration than the patients previously treated with infliximab. ${ }^{101}$ However, this study, as well as the PRECiSE 3 and the PRECiSE 4 trials, ${ }^{71,72,80}$ only give indirect information concerning certolizumab pegol's efficacy in infliximab naïve CD patients, and do not directly address the question of switching from infliximab to certolizumab pegol in cases of loss of response to infliximab. ${ }^{102}$ This question was addressed by the WELCOME (26-Week open-label trial Evaluating the clinical benefit and tolerability of certoLizumab pegol induCtiOn and Maintenance in patients suffering from Crohn's disease with prior loss of response or intolErance to infliximab) study which was designed to prospectively evaluate the efficacy of certolizumab pegol in 539 CD patients with moderate to severe disease and secondary failure to infliximab (excluding primary nonresponders). ${ }^{103}$ This prospective, randomized, double-blinded, and placebo-controlled trial evaluated both efficacy and tolerance, at 26 weeks, in patients responding to an open-label induction regimen of certolizumab pegol administered at a dose of $400 \mathrm{mg}$ (subcutaneously) at week 0,2 , and 4 . Responders at week 6 were eligible and randomized to enter into one of the two following groups: treatment with $400 \mathrm{mg}$ of certolizumab pegol each 4 weeks or each 2 weeks. At week $6,62 \%$ of patients were considered as responders $(n=334)$. At the end of the study, $40 \%$ and $37 \%$ of those receiving maintenance treatment for 4 or 2 weeks, respectively, had a clinical response ( $P=0.55$ between these two groups), and $29 \%$ and $30 \%$, respectively, were in clinical remission $(P=0.81){ }^{103}$ Unfortunately, these results were weakened by the absence of a placebo group in the randomized maintenance treatment period. Nevertheless, it seems reasonable to consider certolizumab pegol as an alternative and effective treatment option in CD patients who have lost their response to a first line infliximab treatment regimen.

\section{Safety (and side effects) of anti-TNF-alpha therapy}

Before beginning a monoclonal anti-TNF-alpha antibody treatment, a thorough medical history must be taken and several radiological and biological tests have to be done to reduce, as much as possible, the risk of side effects. A checklist of recommendations before treating a patient has been created in France by the GETAID (Groupe d'Etudes Thérapeutiques des Affections Inflammatoires du tube Digestif). ${ }^{104}$

If there is no contraindication to anti-TNF-alpha antibody therapy, treatment can be started following the usual recommended doses and administration schedule (Table 4). A particular case is represented by patients having a personal history of tuberculosis (TB), or having been in close contact with a subject suffering from primary infection, or finally, those with a positive TB test (tuberculin skin test - or Mantoux test - or QuantiFERON-TB ${ }^{\circledR}$ Gold, which is less affected by immunosuppression than the skin test). These patients may receive a prophylactic TB treatment before anti-TNF-alpha therapy. Several recommendations have been published. For example, in France, the AFSSAPS (Agence Française de Sécurité Sanitaire des Produits de Santé which has been recently renamed Agence Nationale de Sécurité du Médicament et des produits de santé [ANSM], a health regulatory agency which can be compared to the Food and Drug Administration [FDA] in the US) recommended treatment using a combination of oral rifampicin $(10 \mathrm{mg} / \mathrm{kg}$ of body weight/day) and isoniazid ( $4 \mathrm{mg} / \mathrm{kg}$ of body weight/day) for a period of 3 months, or $5 \mathrm{mg} / \mathrm{kg}$ of body weight/day of isoniazid alone for 9 months (in cases of rifampicin toxicity or patients with liver cirrhosis), or in cases of contraindication of isoniazid or isoniazid-resistant Mycobacterium tuberculosis, a regimen combining $10 \mathrm{mg} / \mathrm{kg}$ of body weight/day of rifampicin plus $20 \mathrm{mg} / \mathrm{kg}$ of body weight/day of pyrazinamide for 2 months. ${ }^{105}$ This latter combination treatment should be used only if strictly necessary due to its 
liver toxicity and it needs a close survey of liver biological parameters. This prophylactic treatment should be initiated at least 3 weeks before the first anti-TNF-alpha monoclonal antibody administration. ${ }^{105}$

These practical aspects of anti-TNF-alpha therapy lead us to describe the most frequent side effects that occur in treated patients. A large analysis of 500 patients treated with infliximab infusion for CD was published in $2004^{106}$ and it is important to know that side effects are continuously recorded in the TREAT registry (The Crohn's Therapy, Resource, Evaluation, and Assessment Tool Registry). ${ }^{107}$

\section{Infections}

Numerous opportunistic infections have been reported in CD patients, in particular in those patients on immunosuppressive therapy. ${ }^{108}$ The most frequent anti-TNF-alpha antibody side effects are infectious complications. In the Mayo Clinic experience published in 2004, ${ }^{106} 48$ of 500 patients $(8.2 \%)$ experienced an infectious event attributed to infliximab treatment. Infection was considered as severe (needing antimicrobial treatment and/or hospitalization) in 20 patients (4\%), and two patients had fatal sepsis $(2.8 \%$ in our series, one $\left[1.7 \%\right.$ ] being serious, without any deaths). ${ }^{58,106}$ With adalimumab, serious infections occurred in $2.7 \%$ of patients in the CHARM trial (not statistically significant when compared to the placebo group), ${ }^{65}$ and with certolizumab pegol, results from the PRECiSE 2 trial found that $3 \%$ of patients had severe infectious adverse events. ${ }^{72}$

TB has been the most frequent cause of severe infectious events at the beginning of anti-TNF-alpha therapy. ${ }^{109}$ Fortunately, its frequency decreased after performing a systematic screening, and if needed, a prophylactic treatment before each anti-TNF-alpha treatment was introduced. Prior to systematic screening recommendations, the risk of latent $\mathrm{TB}$ reactivation during anti-TNF-alpha treatment was increased by approximately seven-fold, but this has now decreased by $80 \% .{ }^{110}$ Nevertheless, the risk of reactivation or contraction of TB primary infection remains possible, therefore there is a need to be wary in case of occurrence of clinical symptoms or biological signs of an active TB, in particular: (i) because the screening methods are not $100 \%$ effective (despite the frequent use of the T-cell-based interferon- $\gamma$ assay), and (ii) because these immunocompromised patients may be in contact with asymptomatic patients carrying $M$. tuberculosis during their treatment period. This was the case for one young female patient in our series who developed peritoneal TB after two screenings (the first before infliximab onset, the second after adalimumab's prescription several months after cessation of infliximab for an anaphylactic side effect). Retrospective familial inquiries revealed that during the time that she was treated with adalimumab, her grandfather presented with pulmonary primary infection.

Numerous infectious complications have been described in patients treated with anti-TNF-alpha (or anti-TNF-alpha receptor) therapy, in particular opportunistic infections $(0.3 \%$ to $0.9 \%) .{ }^{106,108,109,111,112}$ They include atypical bacterial infections such as legionellosis, fungal infections (histoplasmosis 30\%, candidiasis 23\%, aspergillosis 23\%), ${ }^{108,112}$ and viral infections. ${ }^{106,108,112}$ It is important to note that the risk of opportunistic infection is increased in cases of treatment combining anti-TNF-alpha monoclonal antibodies with other immunosuppressive treatments such as purine analogues, and in particular steroids. ${ }^{113,114}$

\section{Dermatological side effects}

A wide spectrum of dermatological side effects has been described in therapeutic trials and in clinical practice in patients treated with anti-TNF-alpha blockers both for rheumatologic diseases and IBD. In 2005, Flendrie et al published on a series of rheumatoid arthritis patients amongst whom 25\% (72 patients during 911 patient-years of follow-up) presented with skin lesions, and treatment needed to be stopped in $26 \%{ }^{115}$ Skin infections were the most frequent adverse effect (25.8\%), followed by eczema (15.6\%), and drug-related eruptions (11.7\%). However, although not frequent, malignant tumors represented $3.9 \%$ of dermatological complications, which is not negligible and probably requires physicians to be very attentive to check patients on a regular basis. ${ }^{115}$ In another review, a high frequency of psoriasiform eruptions was reported (40.5\% of palmoplantar pustular psoriasis with plaque-type psoriasis in $33.1 \%$ of patients). ${ }^{116}$

In IBD, a retrospective study of 85 patients (69 with CD, 15 with UC, one with indeterminate colitis) found 23 eczematiform lesions and 62 psoriasiform lesions. ${ }^{59}$ Interestingly, these inflammatory skin lesions appear at higher frequency in patients with personal $(n=24)$ or familial $(n=15)$ history of inflammatory skin disease, and in women (77\%), for both types of lesions. ${ }^{59}$ This latter observation is in accordance with the well described predominance of autoimmune diseases in women. ${ }^{117,118}$ Finally, it is noteworthy that 29 patients $(34 \%)$ had to stop their treatment due to uncontrolled and/or recurrent (in case of switching to another anti-TNF-alpha antibody) inflammatory skin disease. ${ }^{59}$

Although skin lesions were more frequently observed in patients treated with infliximab in this series, ${ }^{59}$ this result should be considered as a potential bias because infliximab 
has been used in Europe for IBD treatment for numerous years before adalimumab and certolizumab pegol. Actually, a series reporting dermatological adverse effects in rheumatic patients indicated that adalimumab may induce a significantly higher number of inflammatory skin lesions than infliximab or etanercept (which is not used for IBD treatment). ${ }^{119}$

The occurrence of these skin lesions raised a number of questions related to its pathogenesis. As anti-TNF-alpha inhibitors have been approved and are increasingly used to treat moderate to severe psoriasis, ${ }^{120}$ it is surprising that they induce paradoxical psoriasiform skin lesions in patients treated with anti-TNF-alpha antibodies for rheumatologic diseases or IBD. Among the hypotheses explaining this paradoxical effect, several authors suggested that inhibition of TNF-alpha may cause uncontrolled interferon- $\gamma$ production by plasmacytoid dendritic interferon-alpha-producing cells infiltrating the skin of patients with psoriasis. ${ }^{121,122}$ Favoring this hypotheses is the fact that increased interferon-alpha expression has been reported in the dermal lesions of rheumatic patients treated with anti-TNF-alpha blockers. ${ }^{123}$ Nevertheless, this does not explain why anti-TNF-alpha inhibitors do not exacerbate psoriasis in patients treated for this clinical reason.

\section{Malignancies}

Strong immunosuppression has been associated with, or at least suspected to be associated with (depending on the agent used), increased cancer risk in patients, especially for those on long-term therapy. As TNF-alpha physiologically induces apoptosis and is considered to play a role in tumor suppression, anti-TNF-alpha monoclonal antibodies were considered to increase this risk. In a meta-analysis, Bongartz et al compared 3493 patients receiving infliximab or adalimumab to 1512 patients receiving a placebo and found a pooled odds ratio of 3.3 for all types of cancers (95\% confidence interval [CI] 1.2-9.1). ${ }^{124}$ In a large population-based study of 47,679 patients (27,559 UC and 20,120 CD patients), the standardized incidence ratios for lymphoma in $\mathrm{CD}$ and UC patients who never received an immunosuppressive therapy were $1.0(n=87)$ and $1.3(n=65)$, respectively. ${ }^{125}$ In rheumatoid arthritis patients, who like IBD patients have a basal risk of lymphomas that is higher than in the general population (standard incidence ratio $[\mathrm{SIR}] \sim 2$ ), the risk in those exposed to anti-TNF-alpha therapy was not increased after adjustment for age, sex, and disease duration. ${ }^{126}$ In CD patients, considering the data from the TREAT registry, there was no significant increase in the risk of development of lymphoma (relative risk [RR] 0.74, 95\% CI 0.24-2.29). ${ }^{127-129}$ In a French national cohort of 19,486 IBD patients (CESAME
[Cancers et Surrisque Associe aux Maladies inflamatoires intestinales En France ] cohort), the overall risk of developing a primary intestinal lymphoproliferative disorder has been shown to be increased with a SIR of 17.51 (95\% CI 6.43-38.11, $P=0.0001)$, especially in patients exposed to thiopurines (SIR 49.52, 95\% CI 13.49-126.8, $P=0.0001$ ), with no increased risk in patients naïve for thiopurines. ${ }^{130}$ Finally, a meta-analysis of 26 studies (including 8905 CD patients) reported that although the risk of lymphoma was significantly increased in patients treated with any anti-TNFalpha therapy when compared to the general population (SIR 3.23, 95\% CI 1.5-6.9), this risk was not significantly higher than the risk in patients only exposed to thiopurine therapy (SIR 1.7, 95\% CI 0.5-7.1). ${ }^{131}$ Nevertheless, specific attention should be given to a very rare type of lymphoma, the hepatosplenic T-cell lymphoma. Its very low occurrence does not allow a proper assessment of its actual incidence. ${ }^{132}$ Nevertheless, multiple case reports have been published in CD patients, mostly treated with both thiopurines and antiTNF-alpha antibodies, ${ }^{133-135}$ although several hepatosplenic T-cell lymphomas have been reported in patients receiving only anti-TNF-alpha monotherapy. ${ }^{136}$ In fact, this rare lymphoma seems to occur in a specific population (usually male adolescents or young adults - in the second or third decade treated long-term with both anti-TNF-alpha antibodies and purine analogs) leading some authors to propose expert recommendations, in particular, to avoid prolonged (over 2 years) combination therapy with AZA or 6-MP. ${ }^{137}$ The risk of adalimumab-complicating lymphomas has only been estimated in rheumatoid arthritis with an approximate 3 -fold increased risk reported in the FDA guidelines, but this was compared to the general population and not to a population of rheumatoid arthritis patients naïve of adalimumab. ${ }^{138}$ Currently, to our knowledge (non-hepatosplenic) lymphoma has not been reported in patients treated with adalimumab for IBD. This is also the case for certolizumab pegol. Only one case of lymphoma has been reported in the efficacy and tolerance studies, but it occurred in a patient from the placebo group on thiopurine therapy. ${ }^{71} \mathrm{~A}$ recent review has detailed the overall lymphoma risk in IBD patients. ${ }^{139}$

Currently, other types of cancers, in particular solid tumors (nonmelanoma skin cancers, uterus cervix dysplasia or cancer, etc), have not been significantly associated with anti-TNF-alpha antibody monotherapy in IBD. ${ }^{137,140}$ In contrast, experimental data in animals have suggested that anti-TNF-alpha blockers can protect against the risk of colitis-associated cancer. ${ }^{141}$ However, this result should be treated with particular caution as data has not been published 
in humans to assess such a putative chemopreventative effect of anti-TNF-alpha antibodies.

\section{Antibody formation}

The therapeutic use of anti-TNF-alpha antibodies frequently leads to antibody formation directed against the therapeutic monoclonal antibody. This is a normal immune response by the adaptive immune system against a foreign antibody. This immune response induces the production of human-antihuman antibodies (HAHA): ATI for infliximab and antibodies to adalimumab (ATA) for adalimumab. Antibodies to infliximab and adalimumab are elicited against the hypervariable complementary determining regions of the Fab' portions of the immunoglobulins, thereby neutralizing the therapeutic antibody and decreasing its serum concentration (also known as through levels). ${ }^{142}$ Although the use of other anti-TNFalpha agents (certolizumab pegol, etanercept, golimumab) in rheumatologic diseases reported HAHA production, they did not seem to affect the therapeutic efficacy. ${ }^{143}$ In $\mathrm{CD}$ patients treated with infliximab infusions, ATI formation was reported in as high as $61 \%$ of patients. ${ }^{144}$ Moreover, ATI formation was shown to be associated with an increase in infusion reactions and in secondary loss of response. ${ }^{144}$ Unfortunately, neither ATI formation nor circulating ATI levels correlated with these risks and therefore they cannot be used as sole predictors of anaphylactic reactions or of the length of treatment efficacy. ${ }^{144}$ This study also reported a lower risk of ATI formation in patients concomitantly treated with immunosuppressors (mostly with purine analogs). ${ }^{144}$ In contrast, more recent studies have not found any significant effect of thiopurines on ATI formation. Recently, Nanda et al reported on the results of a meta-analysis evaluating the effects of ATI on clinical outcomes and infliximab through levels in IBD patients. ${ }^{145}$ They found that 13 studies met their inclusion criteria (although all studies had a high risk of bias). The pooled risk ratio for loss of clinical response to infliximab was 3.2 (95\% CI 2.0-4.9) for patients who had ATI $(P<0.0001$ compared to those not developing ATI). This was principally the case for CD patients (risk ratio for ATI-positive patients 3.2, 95\% CI 1.9-5.5, $P<0.0001$ ), and the risk ratio was not statistically different in UC patients (risk ratio 2.2, 95\% CI 0.5-9.0, $P=0.3$ ). ${ }^{145}$ The standardized mean difference in through serum infliximab concentrations between groups was -0.8 ( $95 \% \mathrm{CI}:-1.2$ to -0.4 , $P<0.0001) .{ }^{145}$ These results confirm that ATI formation is associated with a higher risk of loss of response and lower through levels, especially in CD patients. For adalimumab, although it is a fully human monoclonal antibody, the risk of ATA formation remains. In the CLASSIC 2 study, the frequency of ATA formation was low $(2.6 \%$, all in patients without concomitant immunosuppression: $3.8 \%$ in this group). ${ }^{54}$ Although specific data are not available they seem to be very rarely associated with adverse events ie, anaphylactic reactions. ${ }^{146}$ However, data indicate that they could influence the long-term response to adalimumab when combined with the adalimumab's serum through levels.

\section{Infusion reactions}

Infusion reactions only occur with infliximab at an estimated frequency of $6.1 \%$, with approximately $1 \%$ being serious reactions leading to shortness of breath, hypotension, stridor, or exceptionally severe anaphylactic shock. ${ }^{147}$ If not severe, the observed symptoms include erythema, burning sensation or pain, and itching. Prophylactic treatment with antihistaminic drugs, or a single-dose hydrocortisone injection, has been proposed to decrease their occurrence, but this strategy has not been clearly validated. Such reactions are more frequent in patients who have not been on infliximab treatment for more than 4 months. In this case, some experts suggest treating patients with $30 \mathrm{mg} /$ day of prednisolone for 3 days before the first infliximab infusion, as well as the day of infusion, and the day following it, and it seems reasonable not to restart an induction scheme but to prefer a first infusion followed by the second one 8 weeks later.

Delayed hypersensitivity-like reactions have also been reported 3 to 14 days following infusion with infliximab. Clinical symptoms include arthralgia and muscle pain. ${ }^{146,148}$ In general, the occurrence of an infusion reaction requires to stop infliximab treatment and for the patient to switch to another anti-TNF-alpha antibody.

\section{Local reaction at the injection site}

In contrast to infliximab, adalimumab and certolizumab pegol do not lead to infusion reactions. But, as they are injected subcutaneously, a local reaction at the site of injection has been reported in approximately $4 \%$ of patients treated with adalimumab and in $3 \%$ of patients receiving certolizumab pegol. ${ }^{65,70}$ Patients rarely need to stop treatment.

\section{Other adverse reactions}

Other rare adverse effects are possible. Most can be avoided by strictly following contraindications of anti-TNF-alpha treatment. Adverse effects can affect a number of organs and systems. Special attention should be given to patients with congestive heart failure (which is exceptional in young CD or UC patients). Adverse events in general have been detailed in a recent review and include neurological dis- 
eases (demyelination, optic neuritis), autoimmune diseases (systemic lupus erythematosus, sarcoidosis), and several exceptional side effects such as vasculitis, aplastic anemia, or Lupus-like syndrome. ${ }^{148}$ Notably, in a large single center cohort, infliximab treatment was not associated with an increased risk of mortality when compared to IBD patients using nonbiological therapy. ${ }^{148}$

\section{Specific situations}

\section{Pregnancy, lactation, and anti-TNF-alpha monoclonal antibody treatment}

The experience with women exposed to anti-TNF-alpha agents during their pregnancy has progressively increased in the last few years. In most cases, physicians and their patients faced a pregnancy occurring during long-term treatment with an anti-TNF-alpha monoclonal antibody. The second possible situation, ie, the need to initiate an anti-TNF-alpha treatment in a pregnant IBD patient due to occurrence of CD or an UC attack is rare, and the clinical situation often can be managed with corticosteroids during the time of pregnancy. However, patients can be corticosteroid-resistant. All three anti-TNFalpha antibodies used in IBD are classified as FDA Pregnancy category $\mathrm{B}$, which indicates that although no risk is apparent from animal studies, there are no controlled studies of women receiving these agents during pregnancy, and therefore, it is not known if the antibodies can cause fetal harm. However, it is well known that active disease increases the risk of preterm delivery and low birth weight. ${ }^{149,150}$ As declared in the ECCO (European Crohn's and Colitis Organisation) Statement 11C: "If conception occurs at a time of quiescent disease the risk of relapse is the same as in non-pregnant women [...]. If conception occurs at a time of active disease, two-thirds have persistent activity and of them two-third deteriorate [...] etc". ${ }^{151}$ Nevertheless, it is important to note that the incidence of still birth, spontaneous abortion, or congenital malformation is not increased. ${ }^{152}$

For infliximab no significant increase in spontaneous abortion, ectopic pregnancy, still birth, or low birth weight was reported. ${ }^{153,154}$ Two congenital malformations have been observed but these have been related to the severity of the underlying IBD in the women who had severely active disease during pregnancy. No increased risk has been shown with adalimumab. ${ }^{155}$ The important remaining question is that of the potential impact of anti-TNF-alpha antibodies on the fetus and the newborn, as anti-TNF-alpha antibodies have been shown to cross the placental barrier. Therefore, most experts recommend ceasing anti-TNF-alpha antibody treatment during the last trimester of pregnancy to avoid in utero exposure to the antibodies. ${ }^{156-158}$ No data in humans concerning certolizumab pegol are available at this time. To summarize, considering the existing evidence, the overall risk of anti-TNF-alpha therapy with monoclonal antibodies is low, especially if it is restricted to the two first trimesters of pregnancy, and its benefits may outweigh the risks of in utero drug exposure. ${ }^{156-158}$

For breast feeding, the last available consensus considered infliximab and certolizumab pegol to be safe. ${ }^{51}$ The safety data for adalimumab are not yet available. ${ }^{156}$

\section{Anti-TNF-alpha antibodies in pediatric IBD}

As in adult IBD patients, anti-TNF-alpha treatment has been shown to be of great benefit to pediatric IBD patients. Nevertheless, their potential major side effects - especially infection and malignancy - as well as the risk of loss of response which occurs in a substantial number of patients, requires more accurate definition of those patients with the highest benefit/risk profile, to better determine the optimal time for introduction of anti-TNF-alpha therapy and the most appropriate administration regimens, and to provide patients with an individually tailored treatment. In pediatric IBD, infliximab has been the most studied anti-TNF-alpha antibody, and it shows high efficacy for luminal and fistulizing CD (for detailed review, de Bie et al). ${ }^{159}$ For children with refractory $\mathrm{UC}$, data are more limited than for adults. Nevertheless, besides several small and retrospective case series, two prospective cohort studies demonstrated infliximab's role in moderate to severe refractory UC treatment, although infliximab was less effective in pediatric UC than in pediatric CD. ${ }^{160,161}$ Additionally, infliximab has been shown to significantly prevent short-term colectomy in acute severe UC. ${ }^{164}$ Long-term data are not available. Adalimumab has been studied less in children. It is currently not licensed for use in pediatric CD or UC, despite several reports of offlabel use demonstrating its efficacy, usually with relatively short follow-up periods. ${ }^{159}$ Data on certolizumab pegol use in pediatric IBD are not available but studies in children are underway to determine its safety and efficacy. ${ }^{159}$

\section{Conclusion and future developments}

Anti-TNF-alpha monoclonal antibody treatment has dramatically improved the quality of life for IBD patients who are refractory to classical therapies (ie, 5-ASA, corticosteroids, purines, methotrexate, enteral or parenteral nutrition) as well as to less often used drugs (eg, thalidomide, mycophenolate mofetil, etc). However, several questions of practical impact need to be clarified. Although new molecules are currently 
being tested in clinical trials, anti-TNF-alpha monoclonal antibodies are still the most effective therapeutic tools in the armamentarium of all gastrointestinal practitioners confronted with complex and/or resistant forms of IBD. Among the remaining questions, several have received a partial answer. This is the case for the question of "which criteria indicate that we can stop infliximab safely after 1 year of maintenance treatment in $\mathrm{CD}$ patients with inactive disease and concomitantly taking an immunosuppressant?" (the STORI [infliximab diSconTinuation in CrOhn's disease patients in stable Remission on combined therapy with Immunosuppressors] trial), or the question "is the combination of infliximab and AZA better for induction and maintenance treatment of CD than AZA alone or infliximab alone?" (the SONIC study). However, the answers provided by these studies only concern a small population of CD patients. The results of the STORI and SONIC studies cannot be extrapolated to all $\mathrm{CD}$ patients, or be considered as true for the use of other available anti-TNF-alpha antibodies, or be transposed to UC patients, and have not been evaluated on a long-term basis (ie, for a survey period over 12 months). Other questions remain largely unresolved, such as those concerning the improvement of anti-TNF-alpha antibody therapy in the long-term, using the measurement of drug levels (and antidrug antibody levels), ${ }^{163}$ or those questioning the practitioners about the most relevant and long-term predictive therapeutic strategies or goals: "top down or step up", ${ }^{164}$ clinical and/or biological improvement and/or mucosal healing, ${ }^{165,166}$ or impact on disability. ${ }^{167}$

Despite these questions, most of which are currently being addressed in ongoing trials or will be explored in coming studies, anti-TNF-alpha monoclonal antibody therapy has considerably improved the quality of life for a large number of CD and UC patients, with a clear and strong positive benefit/risk balance. It should be considered as an outstanding advance in human medicine.

\section{Disclosure}

Jean-Marie Reimund is (i) a speaker for local continuous medical education sessions (Abbott Laboratories, Merck Sharp \& Dohme, Ferring Pharmaceuticals, Biocodex Inc), (ii) participates on several boards (Ferring Pharmaceuticals, Shire Plc), and (iii) is a principal investigator or French coordinator of several national and international multicenter clinical trials or surveys (Abbott Laboratories, Amgen Inc., AstraZeneca, Janssen Pharmaceuticals, Inc., Millenium Pharmaceuticals, Inc., UCB S.A., Centocor Biotech, Inc.).
Stéphanie Viennot is (i) a speaker for local continuous medical education sessions (Abbott Laboratories, Merck Sharp \& Dohme, Ferring Pharmaceuticals) and (ii) is a subinvestigator in several national and international multicenter clinical trials or surveys (Abbott Laboratories, Amgen Inc., AstraZeneca, Janssen Pharmaceuticals, Inc., Millenium Pharmaceuticals, Inc., UCB S.A., Centocor Biotech, Inc.).

The remaining authors declare no conflicts of interest in this work.

\section{References}

1. Beutler B, Greenwald D, Hulmes JD, et al. Identity of tumor necrosis factor and the macrophage-secreted factor cachectin. Nature. 1985; 316(6028):552-554.

2. Duclos B, Reimund JM, Lang JM, et al. Elevated serum levels of soluble interleukin-2 receptors in Crohn's disease. Gastroenterol Clin Biol. 1990;14(1):104-105.

3. Duclos B, Reimund JM, Lang JM, et al. [Mononuclear cell activation in Crohn's disease. Evaluation using serum assay of neopterin and soluble interleukin-2 receptor.] Activation des cellules mononucléées dans la maladie de Crohn. Evaluation par le dosage sérique de la néoptérine et des récepteurs solubles de l'interleukine-2 (RS-IL-2). Gastroenterol Clin Biol. 1990;14(1):22-27. French.

4. Mueller C, Knoflach P, Zielinski CC. T-cell activation in Crohn's disease. Increased levels of soluble interleukin-2 receptor in serum and in supernatants of stimulated peripheral blood mononuclear cells. Gastroenterology. 1990;98(3):639-646.

5. Crabtree JE, Juby LD, Heatley RV, Lobo AJ, Bullimore DW, Axon AT. Soluble interleukin-2 receptor in Crohn's disease: relation of serum concentration to disease activity. Gut. 1990;31(9):1033-1036.

6. Mahyda YR, Gallagher A, Kurlak L, Hawkey CJ. Plasma and tissue interleukin-2 receptor levels in inflammatory bowel disease. Clin Exp Immunol. 1990;82(1):75-80.

7. Tvede M, Brynskov J. Interleukin-2 stimulation of blood mononuclear cells from patients with inflammatory bowel disease. APMIS. 1991; 99(8):759-764.

8. Murch SH, Lamkin VA, Savage MO, Walker-Smith JA, MacDonald TT Serum concentrations of tumour necrosis factor alpha in childhood chronic inflammatory bowel disease. Gut. 1991;32(8):913-917.

9. Reimund JM, Duclos B, Sapin R, et al. Systemic tumor necrosis factor in Crohn's disease: relationship to disease activity and circulating acute phase reactants. Eur J Gastroenterol Hepatol. 1992;4(11):919-924.

10. Braegger CP, Nicholls S, Murch SH, Stephens S, Macdonald TT. Tumour necrosis factor alpha in stool as a marker of intestinal inflammation. Lancet. 1992;339(8785):89-91.

11. Reinecker HC, Steffen M, Witthoeft T, et al. Enhanced secretion of tumour necrosis factor-alpha, IL-6, and IL-1beta by isolated lamina propria mononuclear cells from patients with ulcerative colitis and Crohn's disease. Clin Exp Immunol. 1993;94(1):174-181.

12. Breese EJ, Michie CA, Nicholls SW, et al. Tumor necrosis factor alphaproducing cells in the intestinal mucosa of children with inflammatory bowel disease. Gastroenterology. 1994;106(6):1455-1466.

13. Reimund JM, Wittersheim C, Dumont S, et al. Mucosal inflammatory cytokine production by intestinal biopsies in patients with ulcerative colitis and Crohn's disease. J Clin Immunol. 1996;103(3): 144-150.

14. Reimund JM, Wittersheim C, Dumont S, et al. Increased production of tumour necrosis factor-alpha, interleukin- 1 beta and interleukin- 6 by morphologically normal intestinal biopsies from patients with Crohn's disease. Gut. 1996;39(5):684-689.

15. Schreiber S, Nikolaus S, Hampe J, et al. Tumour necrosis factor alpha and interleukin 1beta in relapse of Crohn's disease. Lancet. 1999; 353(9151):459-461. 
16. Rutgeerts P, Geboes K, Vantrappen G, Beyls J, Kerremans R, Hiele M. Predictability of postoperative course of Crohn's disease. Gastroenterology. 1990;99(4):956-963.

17. van Dullemen HM, van Deventer SJ, Hommes DW, et al. Treatment of Crohn's disease with anti-tumor necrosis factor chimeric monoclonal antibody (cA2). Gastroenterology. 1995;109(1):129-135.

18. Sandborn WJ, Hanauer SB, Katz S, et al. Etanercept for active Crohn's disease: a randomized, double-blind, placebo-controlled trial. Gastroenterology. 2001;121(5):1088-1094.

19. Rutgeerts P, Lemmens L, Van Assche G, Noman M, Borghini-Fuhrer I, Goedkoop R. Treatment of active Crohn's disease with onercept (recombinant human soluble p55 tumor necrosis factor receptors): results of a randomized, open-label, pilot study. Aliment Pharmacol Ther. 2003;17(2):185-192.

20. Rutgeerts P, Sandborn WJ, Fedorak RN, et al. Onercept for moderate-tosevere Crohn's disease: a randomized, double-blind, placebo-controlled trial. Clin Gastroenterol Hepatol. 2006;4(7):888-893.

21. Targan SR, Hanauer SB, van Deventer SJ, et al. A short-term study of chimeric monoclonal antibody cA2 to tumor necrosis factor alpha for Crohn's disease. N Engl J Med. 1997;337(15):1029-1035.

22. Hanauer SB, Feagan BG, Lichtenstein GR, et al; ACCENT I Study Group. Maintenance infliximab for Crohn's disease: the ACCENT I randomised trial. Lancet. 2002;359(9317):1541-1549.

23. Present DH, Rutgeerts $P$, Targan S, et al. Infliximab for the treatment of fistulas in patients with Crohn's disease. $N$ Engl J Med. 1999;340(18): $1398-1405$

24. Sands BE, Anderson FH, Bernstein CN, et al. Infliximab maintenance therapy for fistulizing Crohn's disease. $N$ Engl J Med. 2004;350(9): 876-885.

25. Rutgeerts P, Sandborn WJ, Feagan BG, et al. Infliximab for induction and maintenance therapy for ulcerative colitis. $N$ Engl J Med. 2005; 353(23):2462-2476

26. Hugot JP, Chamaillard M, Zouali H, et al. Association of NOD2 leucine-reach repeat variants with susceptibility to Crohn's disease. Nature. 2001;411(6837):599-603.

27. Ogura $\mathrm{Y}$, Bonen DK, Inohara N, et al. A frameshift mutation in NOD2 associated with susceptibility to Crohn's disease. Nature. 2001; 411(6837):603-606.

28. Fukata M, Abreu MT. TLR4 signalling in the intestine in health and disease. Biochem Soc Trans. 2007;35(Pt 6):1473-1478.

29. Stappenbeck TS, Rioux JD, Mizoguchi A, et al. Crohn's disease. A current perspective on genetics, autophagy and immunity. Autophagy. 2011;7(4):355-374.

30. Fritz T, Niederreiter L, Adolph T, Blumberg RS, Kaser A. Crohn's disease: NOD2, autophagy and ER stress converge. Gut. 2011;60(11): $1580-1588$

31. Lepage P, Colombel JF, Marteau P, Sime-Ngando T, Dore J, Leclerc M. Dysbiosis in inflammatory bowel disease: a role for bacteriophages? Gut. 2008;57(3):424-425.

32. Sokol H, Pigneur B, Watterlot L, et al. Faecalibacterium prausnitzii is an anti-inflammatory commensal bacterium identified by gut microbiota analysis of Crohn's disease patients. Proc Natl Acad Sci U S A. 2008;105(43):16731-16736.

33. Marteau P, Chaput U. Bacteria for trigger of chronic gastrointestinal disorders. Dig Dis. 2011;29(2):166-171.

34. Salim SY, Söderholm JD. Importance of disrupted intestinal barrier in inflammatory bowel diseases. Inflamm Bowel Dis. 2011;17(1): 362-381.

35. Danese $\mathrm{S}$. New biologic therapy for inflammatory bowel diseases: from bench to bedside. Gut. 2012;61(6):918-932.

36. Bouguen G, Chevaux JB, Peyrin-Biroulet L. Recent advances in cytokines: therapeutic implications for inflammatory bowel diseases. World J Gastroenterol. 2011;17(5):547-556.

37. Rutgeerts P, Vermeire S, Van Assche G. Mucosal healing in inflammatory bowel disease: impossible ideal or therapeutic target? Gut. 2007;56(4):453-455.

38. Pithadia AB, Jain S. Treatment of inflammatory bowel disease (IBD). Pharmacol Rep. 2011;63(3):629-642.
39. Caprilli R, Cottone M, Tonelli F, et al. Two mesalazine regimens in the prevention of post-operative recurrence of Crohn's disease: a pragmatic, double-blind, randomized controlled trial. Aliment Pharmacol Ther. 2003;17(4):517-523.

40. Ardizzone S, Maconi G, Sampietro GM, et al. Azathioprine and mesalamine for prevention of relapse after conservative surgery for Crohn's disease. Gastroenterology. 2004;127(3):730-740.

41. Baudet A, Rahmi G, Bretagne AL, Gloro R, Justum AM, Reimund JM. Severe ulcerative colitis: present medical treatment strategies. Expert Opin Pharmacother. 2008;9(3):447-457.

42. Modigliani R, Mary JY, Simon JF, et al. Clinical, biological and endoscopic picture of attacks of Crohn's disease. Evolution on prednisone. Groupe d'Etudes Thérapeutiques des Affections Inflammatoires Digestives. Gastroenterology. 1990;98(4):811-818.

43. Bouhnik Y, Lémann M, Mary JY, et al. Long-term follow-up of patients with Crohn's disease treated with azathioprine or 6-mercaptopurine. Lancet. 1996;347(8996):215-219.

44. Bradford K, Shih DQ. Optimizing 6-mercaptopurine and azathioprine therapy in the management of inflammatory bowel disease. World $J$ Gastroenterol. 2011;17(37):4166-4173.

45. Chu WM. Tumor necrosis factor. Cancer Lett. 2013;328(2):222-225.

46. Tracey D, Klareskog L, Sasso EH, Salfeld JG, Tak PP. Tumor necrosis factor antagonist mechanisms of action: a comprehensive review. Pharmacol Ther. 2008;117(2):244-279.

47. ten Hove T, van Montfrans C, Peppelenbosch MP, van Deventer SJ. Infliximab treatment induces apoptosis of lamina propria $\mathrm{T}$ lymphocytes in Crohn's disease. Gut. 2002;50(2):206-211.

48. Van den Brande JM, Braat H, van den Brink GR, et al. Infliximab but not etanercept induces apoptosis in lamina propria T-lymphocytes from patients with Crohn's disease. Gastroenterology. 2003;124(7): 1774-1785.

49. Shen C, Assche GV, Colpaert S, et al. Adalimumab induces apoptosis of human monocytes: a comparative study with infliximab and etanercept. Aliment Pharmacol Ther. 2005;21(3):251-258.

50. Horiuchi T, Mitoma H, Harashima S, Tsukamoto H, Shimoda T. Transmembrane TNF-alpha: structure, function and interaction with anti-TNF agents. Rheumatology (Oxford). 2010;49(7):1215-1228.

51. Nessbitt A, Fossati G, Bergin M, et al. Mechanism of action of certolizumab pegol (CDP870): in vitro comparison with other anti-tumor necrosis factor alpha agents. Inflamm Bowel Dis. 2007;13(11): 1323-1332.

52. Mitoma H, Horiuchi T, Tsukamoto H, et al. Mechanisms for cytotoxic effects of anti-tumor necrosis factor agents on transmembrane tumor necrosis factor alpha-expressing cells: comparison among infliximab, etanercept and adalimumab. Arthritis Rheum. 2008;58(5):1248-1257.

53. Vos AC, Wildenberg ME, Duijvestein M, Verhaar AP, van den Brink GR, Hommes DW. Anti-tumor necrosis factor-alpha antibodies induce regulatory macrophages in a Fc region-dependent manner. Gastroenterology. 2011;140(1):221-230.

54. Vos AC, Wildenberg ME, Arjis I, et al. Regulatory macrophages induced by infliximab are involved in healing in vitro and in vivo. Inflamm Bowel Dis. 2012;18(3):401-408.

55. Farrell RJ, Shah SA, Lodhavia PJ, et al. Clinical experience with infliximab therapy in 100 patients with Crohn's disease. Am J Gastroenterol. 2000;95(12):3490-3497.

56. Ricart E, Panaccione R, Loftus EV, Tremaine WJ, Sandborn WJ. Infliximab for Crohn's disease in clinical practice at the Mayo Clinic: the first 100 patients. Am J Gastroenterol. 2001;96(3):722-729.

57. Schnitzler F, Fidder H, Ferrante M, et al. Long-term outcome of treatment with infliximab in 614 patients with Crohn's disease: results from a single-centre cohort. Gut. 2009;58(4):492-500.

58. Deleporte A, Justum AM, Reimund JM. [In "real life", infliximab is also effective in the prevailing luminal forms predominating in Crohn's disease fistulisantes forms: a retrospective study]. Dans la "vraie vie", l'infliximab est aussi efficace dans les formes luminales prédominantes que dans les formes fistulisantes prédominantes de la maladie de Crohn : une étude rétrospective. Presented at the French Congress of Gastroenterology [Journées Francophones d'Hépato-Gastroenterologie et d'Oncologie Digestive]; March 19-22, 2009; Paris, France. In: Gastroenterol Clin Biol. 2009;33(3 Suppl 1):A97. French. 
59. Rahier JF, Buche S, Peyrin-Biroulet L, et al; Groupe d'Etude Thérapeutique des Affections Inflammatoires du Tube Digestif. Severe skin lesions cause patients with inflammatory bowel disease to discontinue anti-tumor necrosis factor therapy. Clin Gastroenterol Hepatol. 2010;8(12):1048-1055.

60. Sparkes MB, Ford AC, Warren L, Greer D, Hamlin J. Efficacy, tolerability, and predictors of response to infliximab therapy for Crohn's disease: a large single centre experience. J Crohns Colitis. 2012;6(2): 143-153.

61. Colombel JF, Sandborn WJ, Reinisch W, et al; SONIC Study Group. Infliximab, azathioprine, or combination therapy for Crohn's disease. N Engl J Med. 2010;362(15):1383-1395.

62. Shale M, Kanfer E, Panaccione R, Ghosh S. Hepatosplenic T cell lymphoma in inflammatory bowel disease. Gut. 2008;57(12): 1639-1641.

63. Hanauer SB, Sandborn WJ, Rutgeerts P, et al. Human anti-tumor necrosis factor monoclonal antibody (adalimumab) in Crohn's disease: the CLASSIC-I trial. Gastroenterology. 2006;130(2):323-333.

64. Sandborn WJ, Hanauer SB, Rutgeerts P, et al. Adalimumab for maintenance treatment of Crohn's disease: results of the CLASSIC II trial. Gut. 2007;56(9):1232-1239.

65. Colombel JF, Sandborn WJ, Rutgeerts P, et al. Adalimumab for maintenance of clinical response and remission in patients with Crohn's disease: the CHARM trial. Gastroenterology. 2007;132(1):52-65.

66. Sandborn WJ, Rutgeerts P, Enns R, et al. Adalimumab induction therapy for Crohn's disease previously treated with infliximab: a randomized trial. Ann Intern Med. 2007;146(12):829-838.

67. Panaccione R, Colombel JF, Sandborn WJ, et al. Adalimumab sustains clinical remission and overall clinical benefit after 2 years of therapy for Crohn's disease. Aliment Pharmacol Ther. 2010;31(12): 1296-1309.

68. Reenaers C, Louis E, Belaiche J, Seidel L, Keshav S, Travis S. Does co-treatment with immunosuppressors improve outcome in patients with Crohn's disease treated with adalimumab? Aliment Pharmacol Ther. 2012;36(11-12):1040-1048.

69. Baker M, Stephens S. Pharmacokinetic properties of the anti-TNF agent certolizumab pegol. Gut. 2006;55(Suppl V):A122.

70. Schreiber S, Rutgeerts P, Fedorak RN, et al; CDP870 Crohn's Disease Study Group. A randomized, placebo-controlled trial of certolizumab pegol (CDP870) for treatment of Crohn's disease. Gastroenterology. 2005;129(3):807-818. Erratum in: Gastroenterology. 2005;129(5): 1808.

71. Sandborn WJ, Feagan BG, Stoinov S, et al; PRECISE 1 Study Investigators. Certolizumab pegol for the treatment of Crohn's disease. New Engl J Med. 2007;357(3):228-238.

72. Schreiber S, Khaliq-Kareemi M, Lawrance IC, et al; PRECISE 2 Study Investigators. Maintenance therapy with certolizumab pegol for Crohn's disease. New Engl J Med. 2007;357(3):239-250. Erratum in: New Engl J Med. 2007;357(13):1357.

73. Lichtenstein GR, Thomsen OØ, Schreiber S, et al; Precise 3 Study Investigators. Continuous therapy with certolizumab pegol maintains remission of patients with Crohn's disease for up to 18 months. Clin Gastroenterol Hepatol. 2010;8(7):600-609.

74. Peyrin-Biroulet L, Deltenre P, de Suray N, Branche J, Sandborn WJ, Colombel JF. Efficacy and safety of tumor necrosis factor antagonists in Crohn's disease: meta-analysis of placebo-controlled trials. Clin Gastroenterol Hepatol. 2008;6(6):644-653.

75. Tozer PJ, Burling D, Gupta A, Phillips RK, Hart AL. Review article: medical, surgical and radiological management of perianal Crohn's fistulas. Aliment Pharmacol Ther. 2011;33(1):5-22.

76. Vida S, Seksik P, Xavier T, et al. Are anti-TNFs able to close enterocutaneous fistula in Crohn's disease? Gastroenterology. 2010; 138(5) (Suppl 1):S533.

77. Sands BE, Blank MA, Diamond RH, Barrett JP, Van Deventer SJ. Maintenance infliximab does not result in increased abscess development in fistulizing Crohn's disease: results from the ACCENT II study. Aliment Pharmacol Ther. 2006;23(8):1127-1136.

78. Colombel JF, Schwarts DA, Sandborn WJ, et al. Adalimumab for the treatment of fistulas in patients with Crohn's disease. Gut. 2009;58(7):940-948
79. Lichtiger S, Binion DG, Wolf DC, et al. The CHOICE trial: adalimumab demonstrates safety, fistula healing, improved quality of life and increased work productivity in patients with Crohn's disease who failed prior infliximab therapy. Aliment Pharmacol Ther. 2010;32(10): 1228-1239.

80. Schreiber S, Lawrance IC, Thomsen OØ, Hanauer SB, Bloomfield R, Sandborn WJ. Randomized clinical trial: certolizumab pegol for fistulas of Crohn's disease-subgroup results from a placebo-controlled study. Aliment Pharmacol Ther. 2011;33(2):185-193.

81. Baudet A, Dupas JL, Brazier F, et al. Infliximab dans le traitement de la rectocolite hémorragique $(\mathrm{RCH})$. Résultats d'une étude rétrospective multicentrique. Gastroenterol Clin Biol. 2008;32(3 Suppl 1):A155. French.

82. Alzafiri R, Holcroft CA, Malolepszy P, Cohen A, Szilagyi A. Infliximab therapy for moderately severe Crohn's disease and ulcerative colitis: a retrospective comparison over 6 years. Clin Exp Gastroenterol. 2011;4:9-17.

83. Rostholder E, Ahmed A, Cheifetz AS, Moss AC. Outcomes after escalation of infliximab therapy in ambulatory patients with moderately active ulcerative colitis. Aliment Pharmacol Ther. 2012;35(5): $562-567$.

84. Reinisch W, Sandborn WJ, Rutgeerts P, et al. Long-term maintenance infliximab therapy for ulcerative colitis: the ACT-1 and -2 extension studies. Inflamm Bowel Dis. 2012;18(2):201-211.

85. Järnerot $\mathrm{G}$, Hertervig E, Friis-Liby I, et al. Infliximab as rescue therapy in severe to moderately severe ulcerative colitis: a randomized, placebocontrolled study. Gastroenterology. 2005;128(7):1805-1811.

86. Baudet A, Savoye G, Lerebours E, et al. L'infliximab est-il efficace dans la rectocolite hémorragique sévère ? Résultats d'une étude rétrospective multicentrique. Gastroenterol Clin Biol. 2008;32(3 Suppl 1):A156. French.

87. Laharie D, Bourreille A, Branche J, et al; Groupe d'Etudes Thérapeutiques des Affections Inflammatoires Digestives. Cyclosporin versus infliximab in patients with severe ulcerative colitis refractory to intravenous steroids: a parallel, open-label randomised controlled trial. Lancet. 2012;380(9857):1909-1915.

88. Reinisch W, Sandborn WJ, Hommes DW, et al. Adalimumab for induction of clinical remission in moderately to severely active ulcerative colitis: results of a randomised controlled trial. Gut. 2011;60(6): 780-787.

89. Reinisch W, Sandborn WJ, Kumar A, Pollack PF, Lazar A, Thakkar RB. 52 -week clinical efficacy with adalimumab in patients with moderately to severely active ulcerative colitis who failed corticosteroids and/or immunosuppressants. Gut. 2011;60:A139-A140.

90. Sandborn WJ, Van Assche GA, Reinisch W, et al. Induction and maintenance of clinical remission by adalimumab in patients with moderate-to-severe ulcerative colitis. J Crohns Colitis. 2011;5(Suppl 1): S123-S124.

91. Sandborn WJ, Van Assche GA, Reinisch W, et al. Adalimumab induces and maintains clinical remission in patients with moderate-to-severe ulcerative colitis. Gastroenterology. 2012;142(2):257-265.

92. Ben-Horin S, Chowers Y. Review article: loss of response to anti-TNF treatments in Crohn's disease. Aliment Pharmacol Ther. 2011;33(9): 987-995.

93. Hanauer SB, Wagner CL, Bala M, et al. Incidence and importance of antibody responses to infliximab after maintenance or episodic treatment in Crohn's disease. Clin Gastroenterol Hepatol. 2004;2(7):542-553.

94. Rutgeerts P, Feagan BG, Lichtenstein GR, et al. Comparison of scheduled and episodic treatment strategies of infliximab in Crohn's disease. Gastroenterology. 2004;126(2):402-413.

95. Farrell RJ, Alsahli M, Jeen YT, Falchuk KR, Peppercorn MA, Michetti P. Intravenous hydrocortisone premedication reduces antibodies to infliximab in Crohn's disease: a randomized controlled trial. Gastroenterology. 2003;124(4):917-924.

96. Vermeire S, Noman M, Van Assche G, Baert F, D’Haens G, Rutgeerts P. Effectiveness of concomitant immunosuppressive therapy in suppressing the formation of antibodies to infliximab in Crohn's disease. Gut. 2007;56(9):1226-1231. 
97. Kopylov U, Mantzanaris GJ, Katasnos KH, et al. The efficacy of shortening the dosing interval to once every six weeks in Crohn's patients losing response to maintenance dose of infliximab. Alimentary Pharmacol Ther. 2011;33(3):349-357.

98. St Clair EW, Wagner CI, Fasanmade AA, et al. The relationship of serum infliximab concentrations to clinical improvement in rheumatoid arthritis: results from ATTRACT, a multicenter, randomized, double-blind, placebo-controlled trial. Arthritis Rheum. 2002;46(6):1451-1459.

99. Panaccione R, Sandborn WJ, D'Haens G, et al. Adalimumab maintains long-term remission in moderately to severely active Crohn's disease after infliximab failure: 1-year follow-up of GAIN trial. Gastroenterology. 2008;134(4 Suppl 1):A133-A134.

100. Ma C, Panaccione R, Heitman SJ, Devlin SM, Ghosh S, Kaplan GC. Systematic review: the short-term and long-term efficacy of adalimumab following discontinuation of infliximab. Aliment Pharmacol Ther. 2009;30(10):977-986.

101. Hanauer SB, Panes J, Colombel JF, Bloomfield R, Schreiber S, Sandborn WJ. Clinical trial: impact of prior infliximab therapy on clinical response to certolizumab pegol maintenance therapy for Crohn's disease. Aliment Pharmacol Ther. 2010;32(3):384-393.

102. Schreiber S. Certolizumab pegol for the treatment of Crohn's disease. Ther Adv Gastroenterol. 2011;4(6):375-389.

103. Sandborn WJ, Abreu MT, D'Haen's G, et al. Certolizumab pegol in patients with moderate to severe Crohn's disease and secondary failure to infliximab. Clin Gastroenterol Hepatol. 2010;8(8):696-702.

104. http://www.getaid.org/MICI_Check-List_anti-TNF.pdf. Accessed March 11, 2013. French.

105. http://ansm.sante.fr/var/ansm_site/storage/original/application/0d7 318ac8b672f9dbac0a7690a213eac.pdf. Accessed March 11, 2013. French.

106. Colombel JF, Loftus EV Jr, Tremaine WJ, et al. The safety profile of infliximab in patients with Crohn's disease: the Mayo clinic experience in 500 patients. Gastroenterology. 2004;126(1):19-31.

107. ClinicalTrials.gov [homepage on the Internet]. US National Institutes of Health. Available from: http://clinicaltrials.gov/ct2/show/study/ NCT00553176. Accessed March 11, 2013.

108. Rahier JF, Ben-Horin S, Chowers Y, et al; European Crohn's and Colitis Organisation (ECCO). European evidence-based consensus on the prevention, diagnosis and management of opportunistic infections in inflammatory bowel disease. J Crohns Colitis. 2009;3(2):47-91.

109. Gómez-Reino JJ, Carmona L, Valderde VR, et al; BIOBADASER Group. Treatment of rheumatoid arthritis with tumor necrosis factor inhibitors may predispose to significant increase in tuberculosis risk: a multicentre active-surveillance report. Arthritis Rheum. 2003;48(8): 2122-2127.

110. Carmona L, Gómez-Reino JJ, Rodríguez-Valverde V, et al; BIOBADASER Group. Effectiveness of recommendations to prevent reactivation of latent tuberculosis infection in patients treated with tumor necrosis factor antagonists. Arthritis Rheum. 2005;52(6): 1766-1772.

111. Hoentjen F, van Bodegraven AA. Safety of anti-tumor necrosis factor therapy in inflammatory bowel disease. World $J$ Gastroenterol. 2009;15(17):2067-2073.

112. Sandborn WJ, Loftus EV. Balancing the risks and benefits of infliximab in the treatment of inflammatory bowel disease. Gut. 2004;53(6): 780-782.

113. Toruner M, Loftus EV Jr, Harmsen WS, et al. Risk factors of opportunistic infections in patients with inflammatory bowel disease. Gastroenterology. 2008;134(4):929-936.

114. Lichstenstein GR, Feagan BG, Cohen RD, et al. Serious infections and mortality in association with therapies for Crohn's disease: the TREAT registry. Clin Gastroenterol Hepatol. 2006;4(5):621-630. Erratum in Clin Gastroenterol Hepatol. 2006;4(7):931.

115. Flendrie M, Vissers WH, Creemers MC, de Jong EM, van de Kerkhof PC, van Riel PL. Dermatological conditions during TNF- $\alpha$-blocking therapy in patients with rheumatoid arthritis: a prospective study. Arthtritis Res Ther. 2005;7(3):R666-R676.
116. Ko JM, Gottlieb AB, Kerbleski JF. Induction and exacerbation of psoriasis with TNF-blockade therapy: a review and analysis of 127 cases. J Dermatol Treat. 2009;20(2):100-108.

117. Whitacre CC. Sex differences in autoimmune disease. Nat Immunol. 2001;2(9):777-780.

118. Zandman-Goddard G, Peeva E, Shoenfeld Y. Gender and autoimmunity. Autoimmun Rev. 2007;6(6):366-372.

119. Harrison MJ, Dixon WG, Watson KD, et al; British Society for Rheumatology Biologics Register Control Centre Consortium; BSRBR. Rates of new-onset psoriasis in patients with rheumatoid arthritis receiving anti-tumor necrosis factor alpha therapy: results from the British Society for Rheumatology Biologics Register. Ann Rheum Dis. 2009;68(2):209-215.

120. Smith CH, Anstey AV, Baker JN, et al. British association of dermatologists' guidelines for biologic intervention for psoriasis 2009. $\mathrm{Br} J$ Dermatol. 2009;161(5):987-1019.

121. Palucka AK, Blanck JP, Bennett L, Pascual V, Banchereau J. Crossregulation of TNF and IFN-alpha in autoimmune diseases. Proc Natl Acad Sci U S A. 2005;102(9):3372-3377.

122. Nestle FO, Conrad C, Tun-Kyi A, et al. Plasmacytoid predendritic cells initiate psoriasis through interferon-alpha production. J Exp Med. 2005;202(1):135-143.

123. de Gannes GC, Ghoreishi M, Pope J, et al. Psoriasis and pustular dermatitis triggered by TNF- $\alpha$ inhibitors in patients with rheumatologic conditions. Arch Dermatol. 2007;143(2):223-231.

124. Bongartz T, Sutton AJ, Sweeting MJ, Buchan I, Matteson EL, Montori V. Anti-TNF antibody therapy in rheumatoid arthritis and the risk of serious infections and malignancies: systematic review and metaanalysis of rare harmful effects in randomized controlled trial. JAMA. 2006;295(19):2275-2285. Erratum in: JAMA. 2006; 295(21):2482.

125. Askling J, Brandt L, Lapidus A, et al. Risk of haematopoietic cancer in patients with inflammatory bowel disease. Gut. 2005;54(5): $617-622$.

126. Askling J, Fored CM, Baecklund E, et al. Haematopoietic malignancies in rheumatoid arthritis: lymphoma risk and characteristics after exposure to tumour necrosis factor antagonists. Ann Rheum Dis. 2005;64(10):1414-1420.

127. Jones JL, Loftus EV Jr. Lymphoma risk in inflammatory bowel disease: is it the disease or its treatment? Inflamm Bowel Dis. 2007;13(10): 1289-1307.

128. Lichtenstein G, Cohen RD, Feagan BG, et al. Safety of infliximab and other Crohn's disease therapies - TREAT Registry data with nearly 15,000 patient-years of follow-up. Gastroenterology. 2006; 130(Suppl 2):A71.

129. Lichtenstein G, Cohen RD, Feagan BG, et al. Safety of infliximab and other Crohn's disease therapies: TREAT Registry data with over 24,575 patient-years of follow-up. Am J Gastroenterol. 2008;103: 1116.

130. Sokol H, Beaugerie L, Maynadié M, et al; CESAME Study Group. Excess primary intestinal lymphoproliferative disorders in patients with inflammatory bowel disease. Inflamm Bowel Dis. 2012;18(11): 2063-2071.

131. Siegel CA, Marden SM, Persing SM, Larson RJ, Sands BE. Risk of lymphoma associated with combination anti-tumor necrosis factor and immunomodulator therapy for the treatment of Crohn's disease: a meta-analysis. Clin Gastroenterol Hepatol. 2009;7(8):874-881.

132. Herrington LJ, Liu L, Abramson O, Jaffe ES. The incidence of hepatosplenic T-cell lymphoma in a large managed care organization, with reference to anti-tumor necrosis factor therapy, Northern California, 2000-2006. Pharmacoepidemiol Drug Saf. 2012;21(1):49-52.

133. Mackey AC, Green L, Liang LC, Dinndorf P, Avigan M. Hepatosplenic T cell lymphoma associated with infliximab use in young patients treated for inflammatory bowel disease. J Pediatr Gastroenterol Nutr. 2007;44(2):265-267.

134. Rosh JR, Gross T, Mamula P, Griffiths A, Hyams J. Hepatosplenic T-cell lymphoma in adolescents and young adults with Crohn's disease: a cautionary tale? Inflamm Bowel Dis. 2007;13(8):1024-1030. 
135. Kotlyar DS, Osterman MT, Diamond RH, et al. A systematic review of factors that contribute to hepatosplenic T-cell lymphoma in patients with inflammatory bowel disease. Clin Gastroenterol Hepatol. 2011;9(1):36-41.

136. Molnár T, Farkas K, Nagy F, Szepes Z, Wittmann T. Lymphomas in two IBD patients treated with anti-TNF- $\alpha$ mono or combination therapy: is hepatosplenic lymphoma really the "old maid"? Inflamm Bowel Dis. 2011;17(9):2025-2026.

137. Beaugerie L. Immunosuppression-related lymphomas and cancers in IBD: how can they be prevented? Dig Dis. 2012;30(4):415-419.

138. Humira ${ }^{\circledR}$ Injection Prescribing Information and Medication Guide [package insert]. Abbott Park, IL: Abbott Laboratories; 2009.

139. Subramaniam K, D'Rozario J, Pavli P. Lymphoma and other lymphoproliferative disorders in inflammatory bowel disease: a review. J Clin Gastroenterol. 2013;28(1):24-30.

140. Lakatos PL, Miheller P. Is there an increased risk of lymphoma and malignancies under anti-TNF therapy in IBD? Curr Drug Targets. 2010;11(2):179-186.

141. Popavinova BK, Kitamura K, Wu Y, et al. Blocking TNF-alpha in mice reduces colorectal carcinogenesis associated with chronic colitis. J Clin Invest. 2008;118(2):560-570.

142. Ben-Horin S, Yavzori M, Katz L, et al. The immunogenic part of infliximab is the $\mathrm{F}(\mathrm{ab}$ ')2, but measuring antibodies to the intact infliximab molecule is more clinically useful. Gut. 2011;60(1):41-48.

143. van Shouwenburg PA, Rispens T, Wolbink GJ. Immunogenicity of anti-TNF biologic therapies for rheumatoid arthritis. Nat Rev Rheumatol. 2013;9(3):164-172.

144. Baert F, Noman M, Vermeire S, et al. Influence of immunogenicity on the long-term efficacy of infliximab in Crohn's disease. $N$ Engl $J$ Med. 2003;348(7):601-608.

145. Cheifetz A, Smedley M, Martin S, et al. The incidence and management of infusion reactions to infliximab: a large center experience. Am J Gastroenterol. 2003;98(6):1315-1324.

146. Steenholdt C, Svenson M, Bendtzen K, et al. Acute and delayed hypersensitivity reactions to infliximab and adalimumab in a patient with Crohn's disease. J Crohn's Colitis. 2012;6(1):108-111.

147. Miehsler W, Novacek G, Wenzl H, et al; Austrian Society of Gastroenterology and Hepatology. A decade of infliximab: the Austrian evidence based consensus of the safe use of infliximab in inflammatory bowel disease. J Crohn's Colitis. 2010;4(3):221-256.

148. Fidder H, Schnitzler F, Ferrante M, et al. Long-term safety of infliximab for the treatment of inflammatory bowel disease: a single-centre cohort study. Gut. 2009;58(4):501-508.

149. Cornish J, Tan E, Tear J, et al. A meta-analysis on the influence on inflammatory bowel disease on pregnancy. Gut. 2007;56(6):830-837.

150. Riis L, Vind I, Politi P, et al; European Collaborative study group on Inflammatory Bowel Disease (EC-IBD). Does pregnancy change the disease course? A study in a European cohort of patients with inflammatory bowel disease. Am J Gastroenterol. 2006;101(7):1539-1545.

151. Van Assche G, Dignass A, Reinisch W, et al; European Crohn's and Colitis Organisation (ECCO). The second European evidence-based Consensus on the diagnosis and management of Crohn's disease: special situations. J Crohn's Colitis. 2010;4(1):63-101.
152. Schnitzler F, Fidder H, Ferrante M, et al. Outcome of pregnancy in women with inflammatory bowel disease treated with anti-tumor necrosis factor therapy. Inflamm Bowel Dis. 2011;17(9):1846-1854.

153. Mahadevan U, Kane S, Sandborn WJ, et al. Intentional infliximab use during pregnancy for induction or maintenance of remission of Crohn's disease. Aliment Pharmacol Ther. 2005;21(6):733-738.

154. Katz JA, Antoni C, Keenan GF, Smith DE, Jacobs SJ, Lichtenstein GR. Outcome of pregnancy in women receiving infliximab for the treatment of Crohn's disease and rheumatoid arthritis. Am J Gastroenterol. 2004;99(12):2385-2392.

155. Johnson DL, Jones KL, Chambers CD, Salas E. Pregnancy outcomes in women exposed to adalimumab: the OTIS autoimmune diseases in pregnancy project. Gastroenterology. 2009;136(Suppl 1):A27.

156. Vermeire S, Carbonnel F, Coulie PG, et al. Management of inflammatory bowel disease in pregnancy. J Crohns Colitis. 2012;6(8): 811-823.

157. Mahadevan U, Cucchiara S, Hyams JS, et al. The London Position Statement of the World Congress of Gastroenterology on Biologic Therapy for IBD with the European Crohn's and Colitis Organisation: pregnancy and pediatrics. Am J Gastroenterol. 2011;106(2): 214-223.

158. Casanova MJ, Chaparro M, Domènech E, et al. Safety of thiopurines and anti-TNF- $\alpha$ drugs during pregnancy in patients with inflammatory bowel disease. Am J Gastroenterol. 2012;108(3):433-440.

159. de Bie CI, Escher JC, de Ridder L. Antitumor necrosis factor treatment for pediatric inflammatory bowel disease. Inflamm Bowel Dis. 2012; 18(5):981-998

160. Turner D, Mack D, Leleiko N, et al. Severe pediatric ulcerative colitis: a prospective multicenter study of outcomes and predictors of response. Gastroenterology. 2010;138(7):2282-2291.

161. Hyams JS, Lerer T, Griffiths A, et al. Outcome following infliximab therapy in children with ulcerative colitis. Am J Gastroenterol. 2010;105(6):1430-1436.

162. Turner D, Griffiths AM. Acute severe ulcerative colitis in children: a systematic review. Inflamm Bowel Dis. 2011;17(1):440-449.

163. Wang SL, Ohrmund L, Hauenstein S, et al. Development and validation of a homogeneous mobility shift assay for the measurement of infliximab and antibodies-to-infliximab levels in patient serum. J Immunol Methods. 2012;382(1-2):177-188.

164. D'Haens GR. Top-down therapy for IBD: rationale and requisite evidence. Nat Rev Gastroenterol Hepatol. 2010;7(2):86-92.

165. Peyrin-Biroulet L, Ferante M, Magro F, et al; Scientific Committee of the European Crohn's and Colitis Organisation. Results from the 2nd Scientific Workshop of the ECCO. I: impact of mucosal healing on the course of inflammatory bowel disease. J Crohns Colitis. 2011;5(5): 477-483.

166. Colombel JF, Rutgeerts P, Reinisch W, et al. Early mucosal healing with infliximab is associated with improved long-term clinical outcomes in ulcerative colitis. Gastroenterology. 2011;141(4):1194-1201.

167. Pariente B, Cosnes J, Danese S, et al. Development of the Crohn's disease damage score, the Lémann score. Inflamm Bowel Dis. 2011;17(6): 1415-1422.

International Journal of Interferon, Cytokine and Mediator Research

Dovepress

\section{Publish your work in this journal}

The International Journal of Interferon, Cytokine and Mediator Research is an international, peer-reviewed, open-access, online journal. The focus of the journal is to publish original research, reports, editorials, reviews and commentaries on all aspects of interferon, cytokine and mediators of inflammation from laboratory science to therapeutic indications and clinical studies. The manuscript management system is completely online and includes a very quick and fair peer-review system, which is all easy to use. Visit http://www.dovepress.com/testimonials.php to read real quotes from published authors. 